\title{
CrystEngComm
}

Check for updates

Cite this: CrystEngComm, 2021, 23, 1969

Received 18th November 2020, Accepted 5th February 2021

DOI: 10.1039/d0ce01679a

rsc.li/crystengcomm

\section{Effect of temperature on the transformation of amorphous calcium magnesium carbonate with near-dolomite stoichiometry into high $\mathrm{Mg}$-calcite $\dagger$}

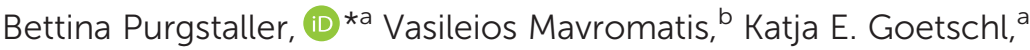 \\ Florian R. Steindl ${ }^{a}$ and Martin Dietzel ${ }^{a}$
}

\begin{abstract}
High $\mathrm{Mg}$-calcite $(\mathrm{HMC})$ is thermodynamically unstable under ambient conditions, yet it has been found in many biogenic and abiotic depositional settings with $\mathrm{Mg}$ contents up to $50 \mathrm{~mol} \%$. The elevated $\mathrm{Mg}$ content of HMC was frequently attributed to an amorphous calcium magnesium carbonate (ACMC) precursor, but the effects of transformation conditions on the $\mathrm{Mg}$ content of HMC are still debated and far from being quantified. Therefore, the transformation of ACMC with near-dolomite stoichiometry $(\sim 48 \mathrm{~mol} \% \mathrm{Mg})$ into $\mathrm{HMC}$ has been studied in a $\mathrm{MgCl}_{2}-\mathrm{NaHCO}_{3}$ buffered solution at moderate $\mathrm{pH}(7.6)$ and temperatures from 10 to $80{ }^{\circ} \mathrm{C}$. The obtained chemical data show that the apparent solubility of ACMC (KACMC) is lower at higher temperature and the relative increase of $K_{\mathrm{ACMC}}$ as a function of the $\mathrm{Mg}$ content is similar between 10 and $80{ }^{\circ} \mathrm{C}$ which can be assessed by the equation: $\log \left(K_{\mathrm{ACMC}}\right)=0.01629 *[\mathrm{Mg}]_{\mathrm{ACMC}}-0.0001096 \mathrm{~T}^{2}+$ $0.0545 \mathrm{~T}-12.919$, where $\mathrm{T}$ is reported in Kelvin and $[\mathrm{Mg}]_{\mathrm{ACMC}}$ refers to the amount of $\mathrm{Mg}$ in $\mathrm{ACMC}$ in mol\%. The Mg content of the final HMC increases from 5 to 40 mol\% with increasing temperature, thus is significantly lower compared to the $\mathrm{Mg}$ content of the ACMC precursor. Our findings argue for a dissolution and re-precipitation process during ACMC transformation, where at higher temperatures the $\mathrm{Mg}$ incorporation into $\mathrm{HMC}$ is enhanced due to (i) the reduced solvation energy barrier of aqueous $\mathrm{Mg}^{2+}$ and (ii) the high prevailing molar $\mathrm{Mg}^{2+} / \mathrm{Ca}^{2+}$ ratio of the solution after its reaction with the ACMC. Notably, the $\mathrm{Mg}^{2+} / \mathrm{Ca}^{2+}$ ratio of the latter solution is controlled by the temperature-dependent solubility of ACMC. Finally, the findings indicate that the nanocrystalline HMCs formed via transformation of ACMC are physically defective from rapid crystal growth and have higher solubilities compared to well-crystallized Mg-bearing calcites.
\end{abstract}

\section{Introduction}

Calcite is the most abundant calcium carbonate $\left(\mathrm{CaCO}_{3}\right)$ mineral in marine and terrestrial environments. ${ }^{1,2}$ In the crystal structure of calcite, $\mathrm{Ca}^{2+}$ can be substituted by other

\footnotetext{
${ }^{a}$ Institute of Applied Geosciences, Graz University of Technology, Rechbauerstraße 12, 8010 Graz, Austria. E-mail: bettina.purgstaller@tugraz.at

${ }^{b}$ Geosciences Environment Toulouse (GET), Observatoire Midi-Pyrénées, Université de Toulouse, CNRS, IRD, UPS, 14 Avenue Edouard Belin, 31400 Toulouse, France $\dagger$ Electronic supplementary information (ESI) available: Table S1: ICSD database code and reference used for mineral phase quantification; Table S2: concentrations of free $\mathrm{Ca}^{2+}$ and $\mathrm{Mg}^{2+}$ ions and calculated $\mathrm{Mg}^{2+} / \mathrm{Ca}^{2+}$ ratios of the experimental solutions; Table S3: activities of $\mathrm{Ca}^{2+}, \mathrm{Mg}^{2+}$ and $\mathrm{CO}_{3}{ }^{2-}$ ions in the experimental solutions and calculated solubility product values $(K)$ for ACMC and HMC; Table S4: summary of solubility data of amorphous $\mathrm{Ca}-(\mathrm{Mg}-)$ carbonates; Fig. S1: XRD pattern, SEM image and thermal analysis of synthesized ACMC; Fig. S2: temporal evolution of $\mathrm{pH}$ and $\mathrm{HCl}$ solution addition to the experimental solution; Fig. S3: XRD patterns of solids collected during ACMC transformation experiments at a $2 \theta$ range from $4^{\circ}$ to $65^{\circ}$; Fig. S4: XRD pattern and SEM image of the reference Coorong dolomite. See DOI: 10.1039/d0ce01679a
}

divalent cations present in natural waters. Predominant in these replacement reactions is the substitution of $\mathrm{Ca}^{2+}$ by $\mathrm{Mg}^{2+} \cdot{ }^{3-5}$ In the literature, calcite containing $>4 \mathrm{~mol} \% \mathrm{Mg}$ is usually referred to as high Mg-calcite ( $\mathrm{HMC} ; \mathrm{Ca}_{1-x} \mathrm{Mg}_{x} \mathrm{CO}_{3}, x$ $>0.04)$, whereas calcite with lower $\mathrm{Mg}$ content is referred to as low Mg-calcite (LMC; $\mathrm{Ca}_{1-x} \mathrm{Mg}_{x} \mathrm{CO}_{3}, x<0.04$ ). ${ }^{5,6}$ Abiogenic HMCs with $<20 \quad \mathrm{~mol} \% \quad \mathrm{Mg}$ form marine cements consolidating sedimentary materials, e.g. in shallow tropical carbonate factories, ${ }^{3}$ in zones affected by anaerobic oxidation of methane ${ }^{7}$ and in coastal sabkha settings. ${ }^{8}$ Biogenic HMCs with up to $25 \mathrm{~mol} \% \mathrm{Mg}$ are a common building material of e.g. skeletons of coralline algae, foraminifers and echinoderms. ${ }^{3,9-12}$ The $\mathrm{Mg}$ content can be even higher (40-45 mol\%) in structural elements of sea urchin teeth. ${ }^{13,14} \mathrm{~A}$ few examples of HMC with up to nearly $50 \mathrm{~mol} \% \mathrm{Mg}$ have been reported in natural depositional settings which are usually rich in microbial activity such as in algal sediments from a hypersaline lake (salt pond) of San Salvador Island, Bahamas ${ }^{15}$ in microbial mats of the Lagoa Vermelha, 
Brazil, ${ }^{16}$ in microbial films of the Seroe Domi Formation of Curacao, The Netherlands ${ }^{17}$ and in sediments of the shallow, alkaline Lake Neusiedl, Austria. ${ }^{18}$ Note here that HMC phases with near-dolomite stoichiometry, but lacking cation ordering, are also referred to as very high Mg-calcite (VHMC) or protodolomite. ${ }^{5}$

Despite several decades of research, the formation of HMC and VHMC in natural systems is a poorly understood process because (i) the (V)HMC structure is destabilized by the uptake of $\mathrm{Mg}^{2+}$ (ref. 19) and (ii) the inorganic precipitation of $\mathrm{HMC}$ with $>20 \mathrm{~mol} \% \mathrm{Mg}$ in the laboratory under ambient conditions remains an enigma as high aqueous $\mathrm{Mg}^{2+} / \mathrm{Ca}^{2+}$ ratios inhibit the nucleation and growth of HMC from solution and favour the precipitation of aragonite $\left(\mathrm{CaCO}_{3}\right) \cdot{ }^{20-23}$ The inhibiting effect of aqueous $\mathrm{Mg}^{2+}$ on the formation of calcite originates from the strong affinity of the $\mathrm{Mg}^{2+}$ ion for the aqueous solution which is reflected by its high hydration Gibbs free energy ${ }^{24}$ and low rate of exchange of water molecules in its hydration sphere. ${ }^{25,26}$ The dehydration of the hydrophilic $\mathrm{Mg}^{2+}$ ion at the lattice growth site is therefore one of the most rate-limiting steps during the formation of (V)HMC.

Experimental studies on mineral formation, however, have shown that besides direct precipitation from solution (classical formation pathway), carbonate minerals can be formed via the transformation of amorphous precursor phases. $^{27,28}$ Evidence for this alternative formation pathway also comes from calcifying organisms, where calcite formation often proceeds through an amorphous calcium carbonate (ACC) precursor phase. ${ }^{29,30}$ In this context, it has been suggested that Mg-containing ACC is a necessary prerequisite for the formation of $\mathrm{HMC}^{10}$ and VHMC. ${ }^{31}$ In most studies, the formation of amorphous calcium magnesium carbonate (ACMC) was induced by mixing a $\mathrm{Na}_{2}$ $\mathrm{CO}_{3}$ solution $(\mathrm{pH}>11)$ with $(\mathrm{Ca}, \mathrm{Mg}) \mathrm{Cl}_{2}$ solutions $(\mathrm{pH}=6-7)$ at room temperature. ${ }^{10,31-35}$ The chemical composition of the initial solution for ACMC synthesis (e.g. $\mathrm{Mg} / \mathrm{Ca}$ ratio, $\mathrm{pH}$ ) has been suggested to control the amount of $\mathrm{Mg}$ incorporated into the ACMC and the final HMC. ${ }^{36-38}$ Specifically, the formation of VHMC via ACMC has been achieved from synthesis in aqueous solutions with high $\mathrm{Mg} / \mathrm{Ca}$ ratios at high $\mathrm{pH}(\sim 10)$, high carbonate-to-calcium ratios $(>2: 1)$ or by thermal treatment $\left(>40{ }^{\circ} \mathrm{C}\right) .{ }^{31,36,38-40}$ However, in most studies, the chemical compositions of the reactive solutions and solids during the formation of ACMC and its transformation into $\mathrm{Mg}$-calcite were not concerned or even not documented. In particular, the effect of temperature on the $\mathrm{Mg}$ content of HMC formed via the amorphous pathway in aqueous solution has not been investigated in earlier studies. In order to better understand the fate of $\mathrm{Mg}$ during the transformation of ACMC into HMC, we investigated the transformation behaviour of synthetic ACMC with neardolomite stoichiometry (48 mol\% $\mathrm{Mg}$ ) in solution at moderate $\mathrm{pH}$ (7.6) and reaction temperatures ranging from 10 to $80 \pm 1^{\circ} \mathrm{C}$. The aim of the present study is to provide a more detailed understanding of the interplay between the chemical composition of (i) ACMC, (ii) the corresponding reactive solution and (iii) (V)HMC formed via ACMC in the apparent aqueous environment. Moreover, the obtained chemical data were used to assess the solubility of ACMC and HMC.

\section{Methods}

\subsection{Synthesis of amorphous calcium magnesium carbonate}

The synthesis of ACMC material with $47.9 \pm 1.5 \mathrm{~mol} \% \mathrm{Mg}$ was carried out by a previously developed protocol. ${ }^{33,41}$ Briefly, a $0.25 \mathrm{M}(\mathrm{Ca}, \mathrm{Mg}) \mathrm{Cl}_{2}$ solution $(\mathrm{Mg} / \mathrm{Ca}$ ratio $=2.1)$ and a $0.25 \mathrm{M} \mathrm{Na}_{2} \mathrm{CO}_{3}$ solution were prepared using $\mathrm{CaCl}_{2} \cdot 2 \mathrm{H}_{2} \mathrm{O}$, $\mathrm{MgCl}_{2} \cdot 6 \mathrm{H}_{2} \mathrm{O}$, and $\mathrm{Na}_{2} \mathrm{CO}_{3}$ chemicals (p.a. Roth) and ultrapure water (Millipore Integral 3; $18.2 \mathrm{M} \Omega \mathrm{cm}^{-1}$ ). The two stock solutions were cooled in a fridge for 4 hours $\left(\mathrm{T}=10 \pm 2{ }^{\circ} \mathrm{C}\right)$. The precipitation of ACMC was induced by pouring $100 \mathrm{~mL}$ of the $(\mathrm{Ca}, \mathrm{Mg}) \mathrm{Cl}_{2}$ solution into a beaker containing $100 \mathrm{~mL}$ of the $\mathrm{Na}_{2} \mathrm{CO}_{3}$ solution. The ACMC was separated from solution by a $0.2 \mu \mathrm{m}$ cellulose filter using a suction filtration unit and was subsequently freeze-dried for 12 hours (Virtis Benchtop $3 \mathrm{~L}$ ). The synthesis protocol was repeated several times until about $20 \mathrm{~g}$ of ACMC were produced. The obtained ACMC material was analysed by X-ray diffraction (Fig. S1A $\dagger$ ) and was stored in a desiccator with silica gel.

\subsection{Experimental setup for ACMC transformation into HMC}

Transformation of ACMC in solution was performed at 10, 20, 40, 60 and $80{ }^{\circ} \mathrm{C}$ (see Table 1). Initially, $50 \mathrm{mM} \mathrm{NaHCO}$ solutions were prepared in $150 \mathrm{~mL}$ gas-tight glass bottles which were placed either in a cooling chamber $\left(10 \pm 2^{\circ} \mathrm{C}\right)$, a temperature-controlled room $\left(20 \pm 2{ }^{\circ} \mathrm{C}\right)$ or in ovens $(40 \pm 2$ ${ }^{\circ} \mathrm{C}, 60 \pm 2{ }^{\circ} \mathrm{C}$ and $80 \pm 2{ }^{\circ} \mathrm{C}$ ) over a period of 24 to $60 \mathrm{~h} .52$ $\mathrm{mL}$ of the pre-cooled/heated $\mathrm{NaHCO}_{3}$ solution was added into a $150 \mathrm{~mL}$ borosilicate glass reactor containing $6.099 \mathrm{~g}$ $\mathrm{MgCl}_{2} \cdot 6 \mathrm{H}_{2} \mathrm{O}$ to obtain a $\mathrm{Mg}$ concentration of $30 \mathrm{mM} .2 \mathrm{~mL}$ of the $\mathrm{NaHCO}_{3}-\mathrm{MgCl}_{2}$ solution was collected with a pipette to measure its initial $\mathrm{Mg}$ and alkalinity concentration (Table 2). The $\mathrm{MgCl}_{2}-\mathrm{NaHCO}_{3}$ solutions exhibit an initial $\mathrm{pH}$ value of $8.02 \pm 0.15$ (Table 2). The reactor was placed in an Easy Max System (Max ${ }^{\mathrm{TM}}$ 102; Mettler Toledo) in order to control the stirring of the solution at $200 \mathrm{rpm}$ and its temperature at 10.0, 20.0, 40.0, 60.0 or $80.0 \pm 0.1{ }^{\circ} \mathrm{C}$ (Fig. 1). Subsequently, $1.5 \mathrm{~g}$ of the synthesized ACMC was introduced into the buffered $\mathrm{NaHCO}_{3}-\mathrm{MgCl}_{2}$ solution (Fig. 1). After a short homogenization period between the ACMC material and the solution, a homogeneous sub-sample of the suspension (2 $\mathrm{mL})$ was collected with a pipette $(t=0.3 \mathrm{~min})$. Subsequently, the $\mathrm{pH}$ of the experimental solution was adjusted to $7.58 \pm$ 0.04 (within $\leq 3 \mathrm{~min}$ ) by computer-controlled titration of a 2 $\mathrm{M} \mathrm{HCl}$ solution (Schott; TitroLine alpha plus) (Fig. S2†). Note here that the $\mathrm{pH}$ of the solution was adjusted to 7.6 to prevent the precipitation of hydrous $\mathrm{Ca}$ - or $\mathrm{Mg}$ - carbonate phases, such as monohydrocalcite and nesquehonite. ${ }^{36,42,43}$ Further homogeneous sub-samples of the experimental suspension $(2 \mathrm{~mL})$ were collected with a pipette at $5 \mathrm{~min}, 11$ 
Table 1 Mineralogical composition of the solids obtained at certain reaction times during experiments performed from 10 to $80{ }^{\circ} \mathrm{C}$. The quantification of high $\mathrm{Mg}$-calcite $(\mathrm{HMC} \text { ), aragonite (ARG) and hydromagnesite (HMG) at } \geq 1 \text { day of reaction time was realized by Rietveld refinement. [Mg] }]_{\mathrm{XRD}}$ of $\mathrm{HMC}$ : Mg content of HMC calculated from the $d_{104}$ reflection according to Goldsmith et al.; ${ }^{44} d_{104}$ : position of the $d_{104}$ reflection of HMC; FWHM ${ }_{d 104}$ : left fullwidth at half-maximum of the $d_{104}$ reflection of HMC

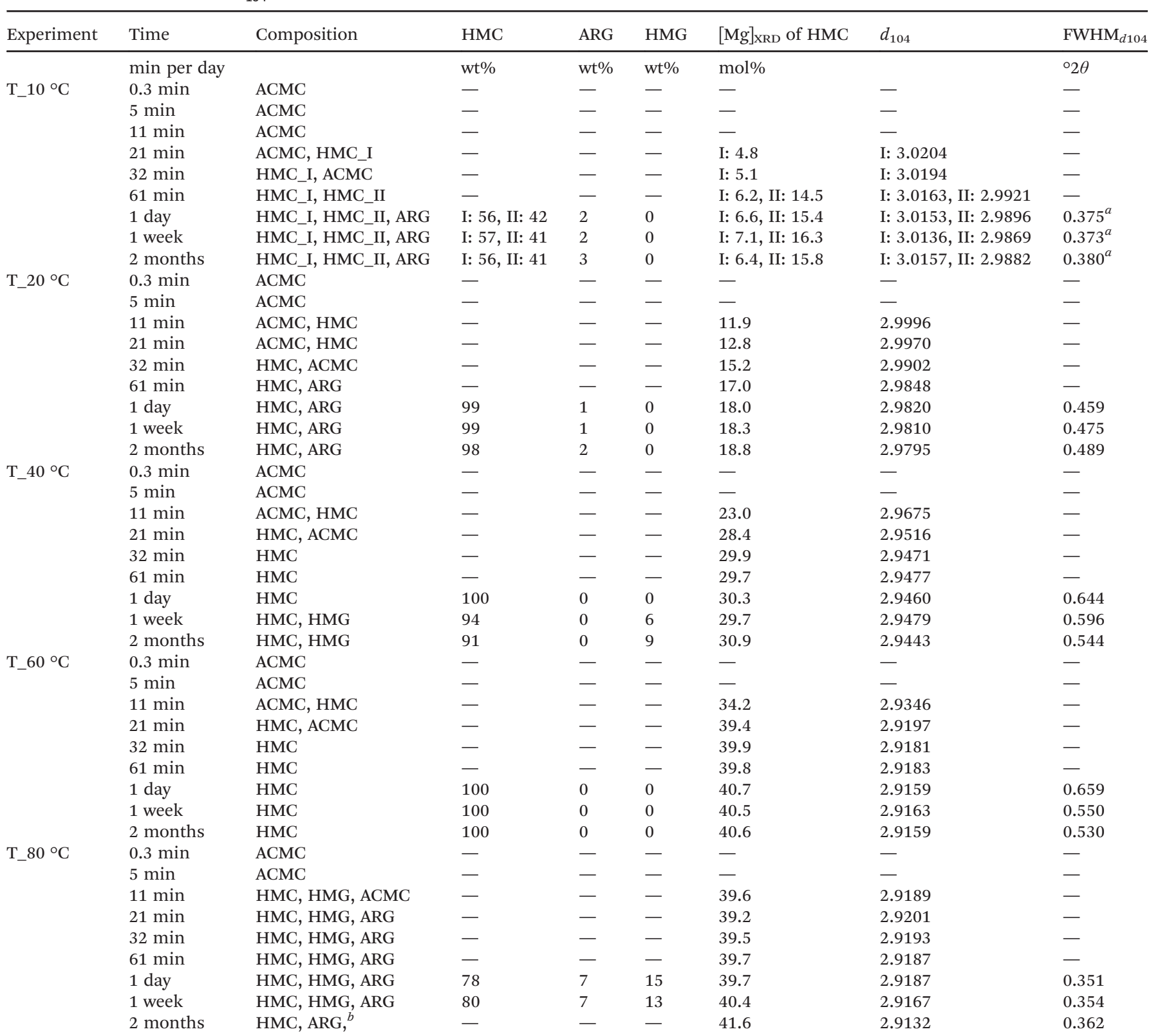

${ }^{a}$ Average FWHM of HMC_I and HMC_II. ${ }^{b}$ Additional phase that could correspond to magnesite.

$\min , 21 \mathrm{~min}, 32 \mathrm{~min}$ and $61 \mathrm{~min}$. After $61 \mathrm{~min}$ of reaction time, the experimental solutions were transferred into 100 $\mathrm{mL}$ gastight bottles which were again placed in the fridge $\left(10 \pm 2{ }^{\circ} \mathrm{C}\right)$, temperature-controlled room $\left(20 \pm 2{ }^{\circ} \mathrm{C}\right)$ and ovens $\left(40 \pm 2{ }^{\circ} \mathrm{C}, 60 \pm 2^{\circ} \mathrm{C}\right.$ and $\left.80 \pm 2^{\circ} \mathrm{C}\right)$ over a period of 2 months. Additional homogeneous sub-samples were collected after 1 day, 1 week and 2 months of reaction time. The solids were separated from the solutions by a 0.2 $\mu \mathrm{m}$ cellulose acetate filter using a suction filtration unit and washed with ethanol. Subsequently, the solids were dried overnight in an oven at $40{ }^{\circ} \mathrm{C}$ and stored in a desiccator with silica gel.

\subsection{Analytical procedures}

Thermogravimetric analyses (TGA) of the freeze-dried ACMC was realized using a PerkinElmer STA8000. The ACMC was heated from $25{ }^{\circ} \mathrm{C}$ to $800{ }^{\circ} \mathrm{C}$ at $10{ }^{\circ} \mathrm{C} \mathrm{min}^{-1}$ in the presence of $99.999 \% \quad \mathrm{~N}_{2}$ atmosphere. The mineralogy of the precipitates collected during the ACMC transformation 
Table 2 Chemical composition of experimental solutions and solids obtained during experiments performed from 10 to $80{ }^{\circ} \mathrm{C}$. $[\mathrm{Ca}]_{\mathrm{aq}}$ and $[\mathrm{Mg}]_{\mathrm{aq}}$ : $\mathrm{Ca}$ and $\mathrm{Mg}$ concentration of the experimental solution; $[\mathrm{Mg}]_{\text {solid: }}$ : $\mathrm{Mg}$ content of the bulk solid determined by chemical digestion (see eqn 1)

\begin{tabular}{|c|c|c|c|c|c|c|}
\hline Experiment & Time & $\mathrm{pH}$ & Alkalinity & {$[\mathrm{Ca}]_{\mathrm{aq}}$} & {$[\mathrm{Mg}]_{\mathrm{aq}}$} & {$[\mathrm{Mg}]_{\text {solid }}$} \\
\hline & min per day & & $\mathrm{mM}$ & $\mathrm{mM}$ & $\mathrm{mM}$ & $\mathrm{mol} \%$ \\
\hline \multirow[t]{10}{*}{$\mathrm{T} \_10^{\circ} \mathrm{C}$} & $0 \mathrm{~min}$ & 8.15 & 49.7 & 0.0 & 29.0 & $47.9 \pm 1.5$ \\
\hline & $0.3 \mathrm{~min}$ & 9.15 & 80.6 & 2.5 & 41.7 & $46.0 \pm 1.5$ \\
\hline & $5 \min$ & 7.52 & 126.1 & 35.1 & 84.3 & $38.0 \pm 1.4$ \\
\hline & $11 \mathrm{~min}$ & 7.55 & 138.8 & 41.3 & 94.3 & $35.4 \pm 1.4$ \\
\hline & $21 \mathrm{~min}$ & 7.31 & 134.3 & 24.5 & 110.1 & $25.5 \pm 1.1$ \\
\hline & $32 \mathrm{~min}$ & 7.59 & 137.8 & 20.1 & 118.1 & $22.3 \pm 1.0$ \\
\hline & $61 \mathrm{~min}$ & 7.53 & 133.8 & 12.9 & 125.2 & $11.4 \pm 0.6$ \\
\hline & 1 day & 7.31 & 109.1 & 2.3 & 122.0 & $13.0 \pm 0.7$ \\
\hline & 1 week & 7.52 & 97.3 & 0.6 & 120.3 & $14.4 \pm 0.7$ \\
\hline & 2 months & 7.77 & 89.9 & 0.3 & 120.7 & $15.5 \pm 0.8$ \\
\hline \multirow[t]{10}{*}{$\mathrm{T} \_20^{\circ} \mathrm{C}$} & $0 \mathrm{~min}$ & 8.17 & 48.4 & 0.0 & 29.1 & $47.9 \pm 1.5$ \\
\hline & $0.3 \mathrm{~min}$ & 9.21 & 77.5 & 2.1 & 41.4 & $45.6 \pm 1.5$ \\
\hline & $5 \min$ & 7.62 & 119.4 & 25.1 & 81.8 & $38.0 \pm 1.4$ \\
\hline & $11 \mathrm{~min}$ & 7.53 & 126.1 & 20.8 & 92.8 & $34.7 \pm 1.4$ \\
\hline & $21 \mathrm{~min}$ & 7.59 & 129.5 & 16.7 & 105.6 & $29.5 \pm 1.2$ \\
\hline & $32 \mathrm{~min}$ & 7.59 & 134.2 & 15.7 & 115.1 & $21.9 \pm 1.0$ \\
\hline & $61 \mathrm{~min}$ & 7.53 & 118.3 & 6.9 & 117.7 & $16.6 \pm 0.8$ \\
\hline & 1 day & 7.49 & 96.2 & 0.9 & 114.2 & $19.0 \pm 0.9$ \\
\hline & 1 week & 7.80 & 88.2 & 0.3 & 111.6 & $20.8 \pm 1.0$ \\
\hline & 2 months & 7.92 & 79.7 & 0.2 & 110.4 & $22.2 \pm 1.0$ \\
\hline \multirow[t]{10}{*}{$\mathrm{T} \_40^{\circ} \mathrm{C}$} & $0 \mathrm{~min}$ & 8.01 & 49.7 & 0.0 & 29.0 & $47.9 \pm 1.5$ \\
\hline & $0.3 \mathrm{~min}$ & 8.85 & 70.2 & 1.7 & 38.3 & $47.0 \pm 1.5$ \\
\hline & $5 \mathrm{~min}$ & 7.59 & 102.1 & 14.2 & 75.3 & $39.3 \pm 1.4$ \\
\hline & $11 \mathrm{~min}$ & 7.60 & 108.3 & 10.5 & 85.5 & $35.5 \pm 1.4$ \\
\hline & $21 \mathrm{~min}$ & 7.59 & 110.4 & 7.8 & 97.1 & $30.4 \pm 1.3$ \\
\hline & $32 \mathrm{~min}$ & 7.55 & 99.5 & 3.1 & 99.0 & $28.8 \pm 1.2$ \\
\hline & $61 \mathrm{~min}$ & 7.58 & 86.4 & 1.1 & 97.0 & $29.6 \pm 1.2$ \\
\hline & 1 day & 7.57 & 60.9 & 0.4 & 85.1 & $33.0 \pm 1.3$ \\
\hline & 1 week & 8.52 & 12.0 & 0.3 & 65.2 & $40.1 \pm 1.4$ \\
\hline & 2 months & 8.39 & 8.1 & 0.3 & 64.8 & $41.2 \pm 1.5$ \\
\hline \multirow[t]{10}{*}{$\mathrm{T} \_60^{\circ} \mathrm{C}$} & $0 \mathrm{~min}$ & 8.00 & 49.6 & 0.0 & 29.2 & $47.9 \pm 1.5$ \\
\hline & $0.3 \mathrm{~min}$ & 8.35 & 60.4 & 1.7 & 32.9 & $47.5 \pm 1.5$ \\
\hline & $5 \mathrm{~min}$ & 7.60 & 80.2 & 6.6 & 58.9 & $43.0 \pm 1.5$ \\
\hline & $11 \mathrm{~min}$ & 7.59 & 83.3 & 5.5 & 65.6 & $41.1 \pm 1.5$ \\
\hline & $21 \mathrm{~min}$ & 7.59 & 73.9 & 3.9 & 67.1 & $40.5 \pm 1.4$ \\
\hline & $32 \mathrm{~min}$ & 7.55 & 57.7 & 1.1 & 64.2 & $40.4 \pm 1.4$ \\
\hline & $61 \mathrm{~min}$ & 7.57 & 45.5 & 0.6 & 61.3 & $41.2 \pm 1.5$ \\
\hline & 1 day & 7.46 & 20.1 & 0.6 & 48.9 & $43.8 \pm 1.5$ \\
\hline & 1 week & 7.46 & 7.5 & 0.5 & 43.3 & $45.2 \pm 1.5$ \\
\hline & 2 months & 7.64 & 3.1 & 0.8 & 42.2 & $45.3 \pm 1.5$ \\
\hline \multirow[t]{10}{*}{$\mathrm{T} \_80^{\circ} \mathrm{C}$} & $0 \mathrm{~min}$ & 7.79 & 48.5 & 0.0 & 29.4 & $47.9 \pm 1.5$ \\
\hline & $0.3 \mathrm{~min}$ & 7.82 & 51.3 & 1.6 & 28.1 & $48.3 \pm 1.5$ \\
\hline & $5 \mathrm{~min}$ & 7.59 & 53.7 & 3.2 & 33.1 & $47.6 \pm 1.5$ \\
\hline & $11 \mathrm{~min}$ & 7.49 & 39.7 & 1.4 & 25.0 & $48.8 \pm 1.5$ \\
\hline & $21 \mathrm{~min}$ & 7.41 & 20.7 & 0.3 & 21.8 & $49.0 \pm 1.5$ \\
\hline & $32 \mathrm{~min}$ & 7.42 & 16.7 & 0.3 & 20.4 & $49.3 \pm 1.5$ \\
\hline & $61 \mathrm{~min}$ & 7.57 & 10.7 & 0.3 & 17.3 & $49.5 \pm 1.5$ \\
\hline & 1 day & 7.87 & 5.6 & 0.3 & 15.7 & $49.8 \pm 1.5$ \\
\hline & 1 week & 7.87 & 6.3 & 0.3 & 16.0 & $49.6 \pm 1.5$ \\
\hline & 2 months & 7.54 & 6.7 & 0.9 & 15.3 & $49.8 \pm 1.5$ \\
\hline
\end{tabular}

experiments was determined by a PANalytical X'Pert PRO diffractometer using Co-K $\alpha$ radiation $(40 \mathrm{~mA}, 40 \mathrm{kV})$ at a $2 \theta$ range from 4 to $85^{\circ}$ with a step size of $0.008^{\circ} 2 \theta$ and $40 \mathrm{~s}$ count time per step. The mineral phases of the reaction products were quantified using Rietveld refinement (software HighScore Plus, PANalytical) using the crystal structure data given in Table S1.† The estimated analytical uncertainty of the quantification lies within $1 \mathrm{wt} \%$. The refinement values consisted of the specimen displacement, a 7-term polynomial background function and scale factors and lattice parameters for all phases. For major phases, the peak shape was refined using a pseudo-Voigt profile function and peak asymmetry. The preferred orientation of calcite was refined for the (104) plane with the March-Dollase function. If two separate calcite phases were present, all their refined values, except of the scale factor and lattice parameters, were constrained with each other to ensure a stable refinement. The $d$-value and the left full-width at half-maximum (left FWHM, for asymmetric peaks) of the (104) reflection (hereafter referred to as $d_{104}$ and $\mathrm{FWHM}_{d 104}$, respectively) was obtained from the refinement results. The $d_{104}$ value of the calcite phases was used to calculate their $\mathrm{Mg}$ content ([Mg] $\mathrm{XRD}$ ) according to Goldsmith et al. ${ }^{44}$ and this content was then used to adapt the occupancy of $\mathrm{Ca}$ and $\mathrm{Mg}$ in the structure data used for the refinement. Note that the accuracy of the determination of the $d_{104}$ value and the $\mathrm{FWHM}_{d 104}$ is limited by the step size of the XRD measurement $\left(0.008^{\circ} 2 \theta\right)$.

Selected precipitates were gold-coated and imaged using a scanning electron microscope (SEM, ZEISS DSM 982 Gemini). The total alkalinity of the experimental solutions was measured by a Schott TitroLine alpha plus titrator using a $10 \mathrm{mM} \mathrm{HCl}$ solution with a precision of $\pm 2 \%$. The aqueous $\mathrm{Ca}$ and $\mathrm{Mg}$ concentrations of experimental solutions and solids (digested in $6 \% \mathrm{HNO}_{3}$ ) were determined using inductively coupled plasma optical emission spectrometry (ICP-OES, Perkin Elmer Optima $8300 \mathrm{DV}$ ) with an analytical precision of $\pm 3 \%$ for $\mathrm{Ca}$ and $\mathrm{Mg}$ analyses. The $\mathrm{Mg}$ content of the bulk solid $\left([\mathrm{Mg}]_{\text {solid }}\right.$ in mol\%, Table 2) was calculated according to the equation:

$$
[\mathrm{Mg}]_{\text {solid }}=\frac{[\mathrm{Mg}]_{\mathrm{S}}}{[\mathrm{Mg}]_{\mathrm{s}}+[\mathrm{Ca}]_{\mathrm{s}}} \times 100
$$

where $[\mathrm{Mg}]_{\mathrm{s}}$ and $[\mathrm{Ca}]_{\mathrm{s}}$ are the measured concentrations of $\mathrm{Ca}$ and $\mathrm{Mg}$ of the solid (mol $\mathrm{kg}^{-1}$ ) determined by chemical digestion and ICP-OES analysis.

\subsection{Geochemical modeling}

The aqueous speciation and ion activities of the reactive solutions were calculated using the PHREEQC computer code with the minteq.v4 database. The apparent solubility product $(K)$ for amorphous calcium magnesium carbonate (ACMC, $\mathrm{Ca}_{1-x} \mathrm{Mg}_{x} \mathrm{CO}_{3} \cdot \mathrm{nH}_{2} \mathrm{O}$ ) and high $\mathrm{Mg}$-calcite (HMC, $\mathrm{Ca}_{1-x} \mathrm{Mg}_{x^{-}}$ $\mathrm{CO}_{3}$ ) was calculated using the equation

$$
K=\left(\mathrm{aCa}^{2+}\right)^{1-x}\left(\mathrm{aMg}^{2+}\right)^{x}\left(\mathrm{aCO}_{3}^{2-}\right)
$$

where $\mathrm{aCa}^{2+}, \mathrm{aMg}^{2+}$ and $\mathrm{aCO}_{3}{ }^{2-}$ are the activities of $\mathrm{Ca}^{2+}$, $\mathrm{Mg}^{2+}$ and $\mathrm{CO}_{3}{ }^{2-}$ ions in solution, respectively and $\mathrm{x}$ is the mole fraction of $\mathrm{Mg}$ in the precipitated solid (for HMC: $[\mathrm{Mg}]_{\mathrm{XRD}}$ in Table 1; for ACMC: $[\mathrm{Mg}]_{\text {solid }}$ in Table 2). In the latter case the $\mathrm{Mg}$ and $\mathrm{Ca}$ content of the solid was measured by acid digestion and subsequent ICP-OES analysis, thus representing bulk composition ion-balanced by cation ions. Although water molecules are present in ACMC, the activity 


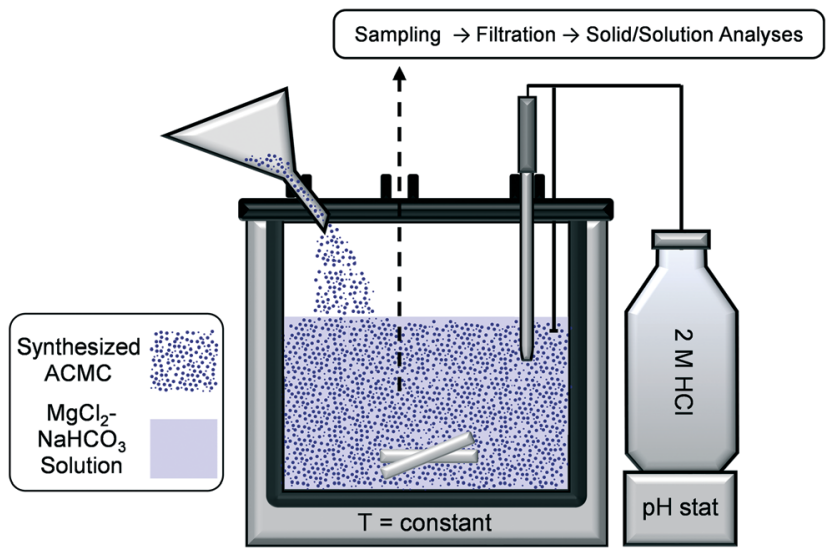

Fig. 1 Experimental setup used for transformation of amorphous calcium magnesium carbonate (ACMC). Synthesized ACMC standard material $\left(\mathrm{Ca}_{0.52} \mathrm{Mg}_{0.48} \mathrm{CO}_{3} \cdot 0.67 \mathrm{H}_{2} \mathrm{O}\right)$ was introduced in a $\mathrm{MgCl}_{2}-\mathrm{NaHCO}_{3}$ buffered solution at $10,20,40,60$ or $80{ }^{\circ} \mathrm{C}$. Subsequently, the $\mathrm{pH}$ of the experimental solution was adjusted to $7.58 \pm 0.04$ by automatic titration of a $2 \mathrm{M} \mathrm{HCl}$ solution.

of water $\left(\mathrm{aH}_{2} \mathrm{O}\right)$ was not included in eqn 2 (see also Purgstaller et $\left.a l .{ }^{33}\right)$. The activity of water $\left(\mathrm{aH}_{2} \mathrm{O}\right)$ was assumed to be equal to unity, in agreement with the estimated $\mathrm{aH}_{2} \mathrm{O}$ values of $0.995 \pm$ 0.002 of all experimental solutions. It is also worth pointing out that the term solubility product $(K)$ is used herein to be comparable to $K$ values of crystalline phases, although this term is not necessarily valid for amorphous solids. ${ }^{28}$

\section{Results}

\subsection{Solid phase characterization}

Scanning electron microscope observations of the synthesised ACMC (47.9 $\pm 1.5 \mathrm{~mol} \% \mathrm{Mg})$ solid reveal spherical particles with $<100 \mathrm{~nm}$ in size (Fig. S1B $\dagger$ ) similar to synthetic amorphous calcium (magnesium) carbonate reported by other authors. ${ }^{37,41,45}$ The water content of the ACMC determined by thermal analysis is $0.67 \pm 0.01$ moles per unit formula (Fig. $\mathrm{S} 1 \mathrm{C} \dagger$ ), thus, its stoichiometric formula can be written as $\mathrm{Ca}_{0.52} \mathrm{Mg}_{0.48} \mathrm{CO}_{3} \cdot 0.67 \mathrm{H}_{2} \mathrm{O}$. This water content is in good agreement with that of the ACMC $\left(\mathrm{Ca}_{0.47^{-}}\right.$ $\left.\mathrm{Mg}_{0.53} \mathrm{CO}_{3} \cdot 0.66 \mathrm{H}_{2} \mathrm{O}\right)$ precipitated by Purgstaller et al. ${ }^{33}$

$\mathrm{X}$-ray diffraction (XRD) patterns of the solids collected during the ACMC transformation experiments are shown in Fig. 2 at a $2 \theta$ range from $33^{\circ}$ to $37^{\circ}$, while overview XRD patterns $\left(2 \theta\right.$ range $\left.=4-65^{\circ}\right)$ are displayed in Fig. S3. $\dagger$ The XRD patterns indicate the sole occurrence of ACMC for $11 \mathrm{~min}$ in experiment $\mathrm{T}_{-} 10{ }^{\circ} \mathrm{C}$ (Fig. $2 \mathrm{~A}$ and $\mathrm{S} 3 \mathrm{~A} \dagger$ ) and for $5 \mathrm{~min}$ in experiments performed at $\geq 20{ }^{\circ} \mathrm{C}$ (Fig. 2B-E and S3B-E $\dagger$ ). Subsequently, XRD peaks appear due to the transformation of ACMC into high Mg-calcite (HMC) and partly into aragonite (ARG) and hydromagnesite (HMG). XRD analyses reveal that for all experiments at $\leq 60^{\circ} \mathrm{C}$, the reaction products consist mainly of HMC ( $\geq 98 \mathrm{wt} \%)$ and traces of ARG $(<2 \mathrm{wt} \%)$ (Table 1). In experiment $\mathrm{T}_{-} 10{ }^{\circ} \mathrm{C}$ two peaks were detected in the XRD pattern corresponding to high $\mathrm{Mg}$-calcites with distinct $\mathrm{Mg}$ contents, hereafter mentioned as HMC_I and HMC_II (Table 1 and Fig. 2A). The reflection peaks of HMC_I appear in the XRD pattern at $\geq 21 \mathrm{~min}$ (during ACMC transformation), while those of HMC_II can be detected at $\geq 61$ min of reaction time (Fig. $2 \mathrm{~A}$ and $\mathrm{S} 3 \mathrm{~A} \dagger$ ). Note that in experiment $\mathrm{T}_{-} 40^{\circ} \mathrm{C}$, minor amounts of HMG (9 wt\%) were detected beside HMC and ARG after 2 weeks of reaction time (Table 1 , Fig. S3C $\dagger$ ). At $80{ }^{\circ} \mathrm{C}, \mathrm{XRD}$ patterns show the transformation of ACMC into HMC, HMG and ARG which account for 78, 15 and $7 \mathrm{wt} \%$, respectively, after 1 day of reaction time (Fig. S3E; $\dagger$ Table 1). After 2 months of reaction time, the presence of HMG was no longer detected (Fig. S3E $\dagger$ ). Instead, a reflection peak at $2.77 \AA$ indicates the presence of new phase (labeled as * in Fig. S3E $\dagger$ ), which could correspond to magnesite $\left(\mathrm{MgCO}_{3}\right){ }^{2}$ Indeed, earlier studies reported the formation of magnesite by the transformation of pre-existing hydrated Mg-carbonate phases such as hydrogmagnesite and dypingite at elevated temperatures (e.g. Montes-Hernandez et ll. $^{46}$ ).

Fig. $2 \mathrm{~F}$ shows that the XRD reflection peaks of the final HMCs are broader in comparison to the reference calcite (Merck). This observation is confirmed by comparing the FWHM $_{d 104}$ values, which shows that the $\mathrm{FWHM}_{d 104}$ is higher for the HMCs (0.351-0.644; Table 1) than for the reference calcite (0.094). The obtained $\mathrm{FWHM}_{d 104}$ values of the HMCs however are similar to that determined for the reference Coorong dolomite $\left(\right.$ FWHM $_{d 104}=0.649$; Fig. S4A $\dagger$ ). Broad XRD reflection peaks are referred to non-ideal crystal structure phenomena which can be caused by small (nanocrystalline) particle sizes $^{39,40,47}$ and inhomogeneities in the $\mathrm{Ca}$ and $\mathrm{Mg}$ composition $^{48}$ of the crystalline solid. Indeed, the broad XRD peaks obtained for the HMCs and the reference Coorong dolomite (Fig. 2F) can result from their small crystal sizes: SEM images reveal aggregates composed of nanocrystals with $<100$ and $<300 \mathrm{~nm}$ in size for the HMCs (Fig. 3D) and the Coorong dolomite (Fig. $\mathrm{S} 4 \mathrm{~B} \dagger$ ), respectively.

To get insights into the evolution of the $\mathrm{Mg}$ content of the forming HMC via ACMC, the characteristic $d_{104}$-peak value of HMC was used to calculate its $\mathrm{Mg}$ content ([Mg] $]_{\mathrm{XRD}}$ ) according to Goldsmith et al. ${ }^{44}$ (Table 1). The Mg content of the HMCs obtained after 1 day of reaction time is higher at elevated temperature as indicated by lower $d_{104}$-values (corresponds to higher $2 \theta$ values in Fig. $2 \mathrm{~F}$ ). Note that a maximum concentration of $40 \pm 1 \mathrm{~mol} \% \mathrm{Mg}$ in $\mathrm{HMC}$ was obtained in experiments $\mathrm{T} \_60{ }^{\circ} \mathrm{C}$ and $\mathrm{T} \_80{ }^{\circ} \mathrm{C}$ (Table 1 ). In experiment $\mathrm{T} \_10{ }^{\circ} \mathrm{C}$, the HMC_I that was detected in the samples collected at $\geq 21 \mathrm{~min}$ exhibits $6 \pm 1 \mathrm{~mol} \% \mathrm{Mg}$, which is $\sim 9 \mathrm{~mol} \%$ lower than the $\mathrm{Mg}$ content of HMC_II $(15 \pm 1$ mol\%) that was detected in the samples obtained at $\geq 61 \mathrm{~min}$ of reaction time (Fig. 2A, Table 1). Rietveld refinement of the reaction products after 1 day shows that the amount of HMC_I (7 mol\% Mg) and HMC_II (15 mol\% Mg) is 56 and 42 wt $\%$, respectively (Table 1). In experiments performed between $20{ }^{\circ} \mathrm{C}$ and $60{ }^{\circ} \mathrm{C}$, the initial HMC phase that was detected beside ACMC (at $11 \mathrm{~min}$ in Fig. 2B-E; Table 1) shows a significant lower $\mathrm{Mg}$ content than the HMC that was obtained during ACMC transformation (Table 1). This indicates that the $\mathrm{Mg}$ uptake in $\mathrm{HMC}$ is not uniform 

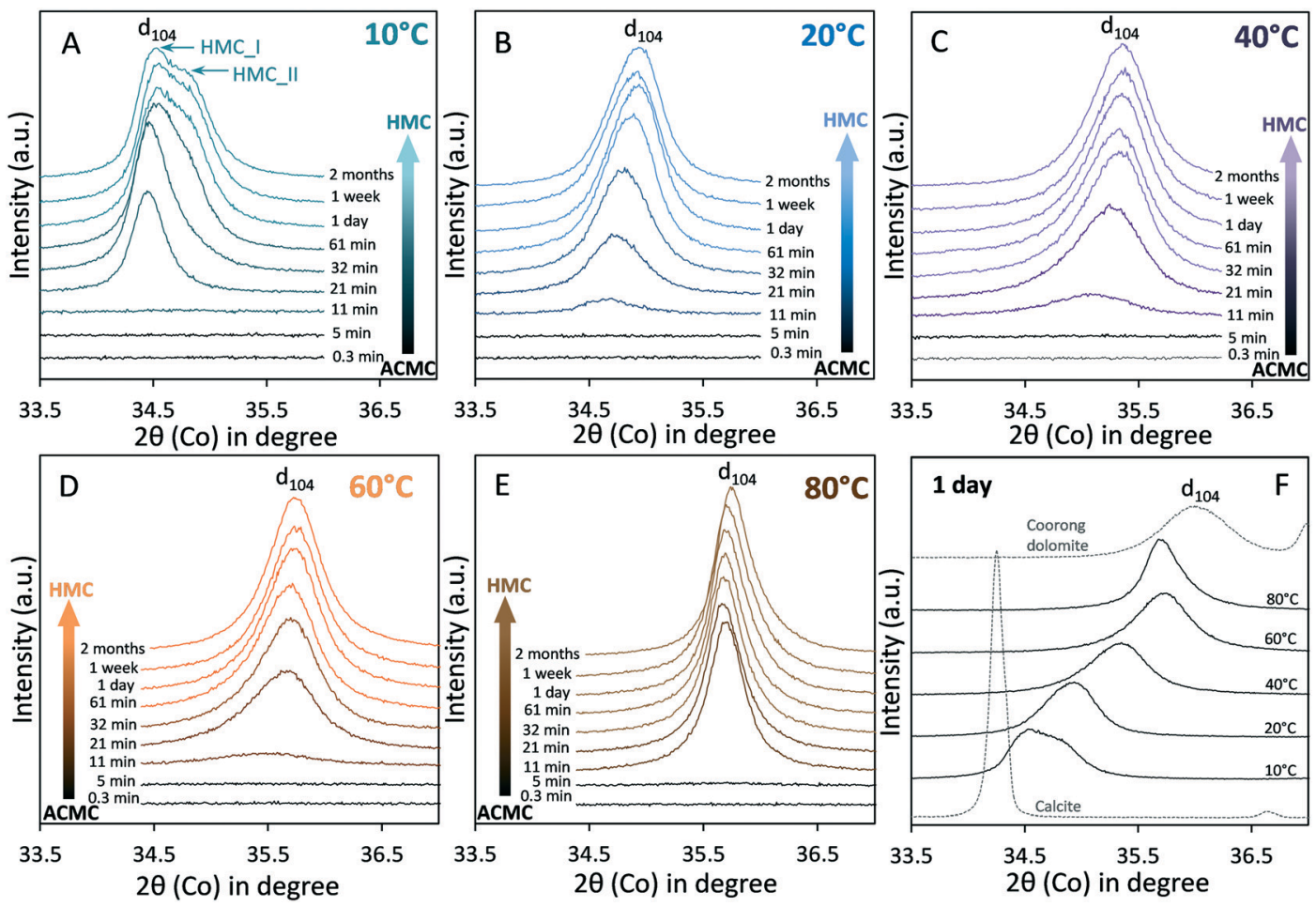

Fig. 2 X-ray diffraction pattern showing the evolution of the $d_{104}$ peak reflection of high Mg-calcite (HMC) formed via transformation of amorphous calcium magnesium carbonate (ACMC) at (A) $10^{\circ} \mathrm{C}$, (B) $20^{\circ} \mathrm{C}$, (C) $40^{\circ} \mathrm{C}$, (D) $60^{\circ} \mathrm{C}$ and (E) $80{ }^{\circ} \mathrm{C}$. Xrd pattern from $4{ }^{\circ}$ to $65^{\circ} 2 \theta$ are shown in Fig. S3. $\uparrow$ Note that the $d_{104}$-value of the final HMC (F) is generally decreasing at higher temperature (increasing $2 \theta$ values) due to elevated Mg content (Goldsmith et al. ${ }^{44}$ ). The X-ray diffraction peaks of the HMCs are broader in comparison to the reference calcite (Merck), but are similar to the reference Coorong dolomite (South Australia).

throughout the transformation process but ends up in HMC with distinct $\mathrm{Mg}$ content. In contrast, in experiment $\mathrm{T} \_80^{\circ} \mathrm{C}$, the HMCs show no significant change in the $[\mathrm{Mg}]_{\mathrm{XRD}}$ values during the experimental run (Table 1).

Scanning electron microscope images show that in experiments performed at $\leq 20{ }^{\circ} \mathrm{C}$, the precipitates obtained at $5 \mathrm{~min}$ of reaction time consist of amorphous spherical particles (Fig. 3A), similar to the synthesized ACMC standard material (Fig. S1B $\dagger$ ). In experiments performed $\geq 40{ }^{\circ} \mathrm{C}$, traces of HMC or HMG nanocrystals were observed beside the ACMC particles at $5 \mathrm{~min}$ of reaction time (Fig. 3A), although XRD results show that the solids obtained at $5 \mathrm{~min}$ are solely amorphous (Fig. 2C-E). The HMC $\left(\mathrm{T}_{-} 40{ }^{\circ} \mathrm{C}\right.$ and $\left.\mathrm{T}_{-} 60{ }^{\circ} \mathrm{C}\right)$ consists of spindle-shaped aggregates composed of nanocrystals, whereas the HMG crystals $\left(\mathrm{T}_{-} 80{ }^{\circ} \mathrm{C}\right)$ show a plate-like morphology. These morphologies are similar to those observed for HMC and HMG obtained at a later stage in the experimental runs (Fig. 3B-D). At a reaction time of 21 min (Fig. 3B), large amounts of spherical ACMC particles were observed in the precipitates obtained in experiments performed at $\leq 20{ }^{\circ} \mathrm{C}$, whereas at $\geq 40{ }^{\circ} \mathrm{C}$ ACMC was rarely observed in the collected solids. Note here that no ACMC particles were observed in the collected solids at $\geq 21 \mathrm{~min}$ in experiment T_80 ${ }^{\circ} \mathrm{C}$ (Fig. 3B), at $\geq 32 \mathrm{~min}$ in experiments $\mathrm{T}_{-} 40{ }^{\circ} \mathrm{C}$ and $\mathrm{T} \_60{ }^{\circ} \mathrm{C}$ (not shown) and at $\geq 61 \mathrm{~min}$ in experiments $\mathrm{T}_{-} 10$ ${ }^{\circ} \mathrm{C}$ and $\mathrm{T} \_20^{\circ} \mathrm{C}$ (Fig. 3C).
SEM images of the final HMC show aggregates composed of spindle-shaped assemblages of nanocrystals at lower temperatures $\left(\leq 20{ }^{\circ} \mathrm{C}\right)$, whereas at higher temperatures $\left(\geq 40{ }^{\circ} \mathrm{C}\right)$ the HMC-nanocrystals coalesced into spheroidal aggregates (Fig. 3C and D). These spindle-shaped and spherical morphologies are consistent with those of high $\mathrm{Mg}$ calcites formed via amorphous precursors from previous studies. ${ }^{39,48-51}$ In experiment $\mathrm{T}_{-} 10{ }^{\circ} \mathrm{C}$, large amounts of star-shaped aggregates composed of linearly arranged nanoparticles were detected beside the spindle-shaped HMC aggregates (Fig. 3D). These star-shaped aggregates most likely correspond to HMC_II that was detected beside HMC_I in the XRD-pattern at $\geq 61 \mathrm{~min}$ in experiment $\mathrm{T}_{-} 10^{\circ} \mathrm{C}$ (Fig. 2A). Trace amounts of those aggregates could also be observed in the final solids of experiments $\mathrm{T}_{-} 20{ }^{\circ} \mathrm{C}$ and $\mathrm{T}_{-} 40{ }^{\circ} \mathrm{C}$ (Fig. 3D). Note here that the aragonite detected in experiments $\mathrm{T} \_10{ }^{\circ} \mathrm{C}, \mathrm{T} \_20{ }^{\circ} \mathrm{C}$ and $\mathrm{T} \_40{ }^{\circ} \mathrm{C} \quad(2-7 \mathrm{wt} \%$, Table 1) could not be found in SEM images.

\subsection{Chemical evolution of the reactive solutions and solids}

The addition of ACMC into the $\mathrm{MgCl}_{2}-\mathrm{NaHCO}_{3}$ solutions induced an increase of $\mathrm{pH}$ as well as of $\mathrm{Ca}, \mathrm{Mg}$ and alkalinity concentrations (at $0.3 \mathrm{~min}$ in Fig. $4 \mathrm{~A}-\mathrm{C}$, Table 2) which is attributed to the dissolution of ACMC. At lower temperatures, higher amounts of ACMC likely dissolved as it is indicated by higher $\mathrm{Ca}, \mathrm{Mg}$ and alkalinity concentrations at $0.3 \mathrm{~min}$ of 


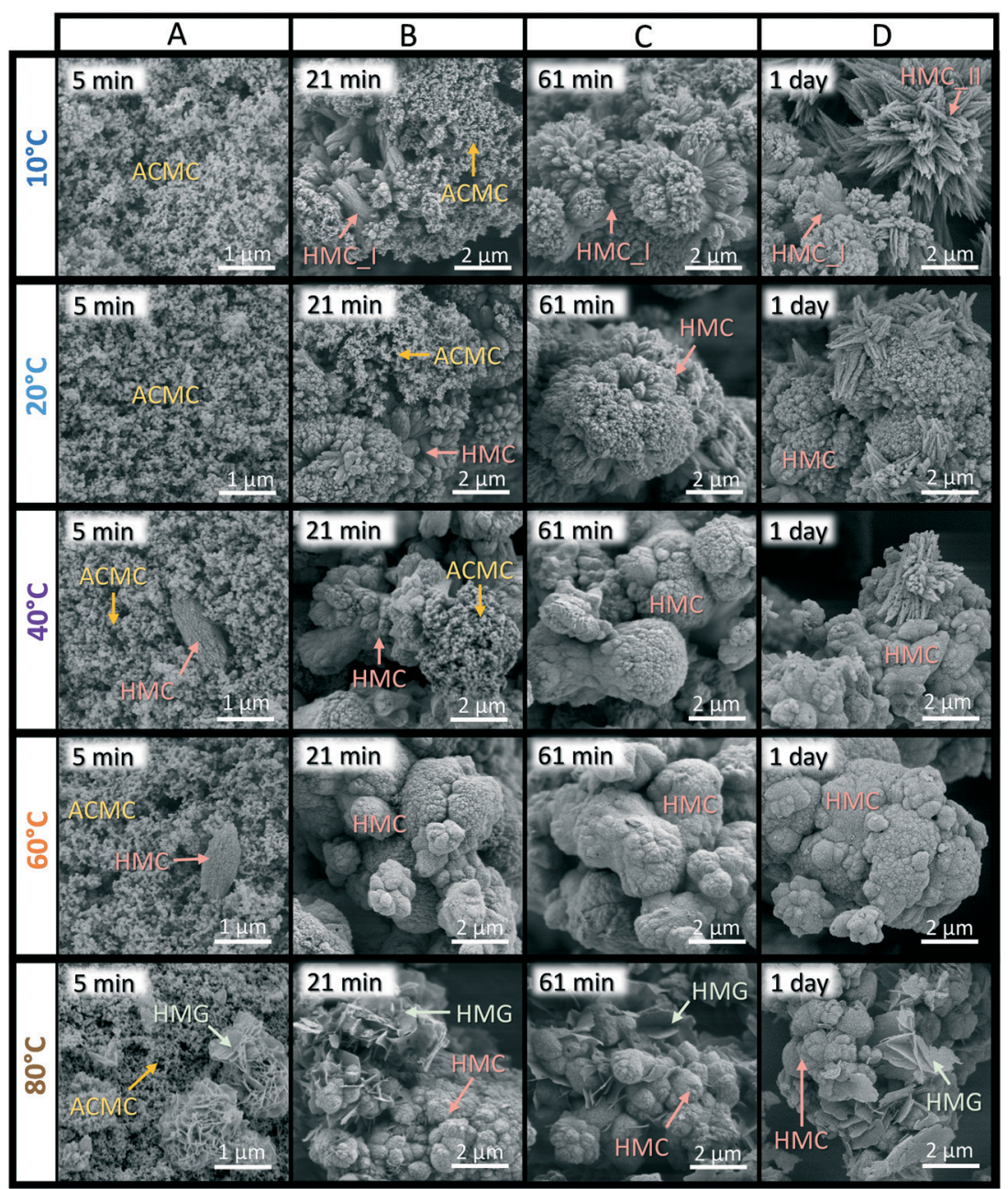

Fig. 3 SEM images of solids collected at $5 \mathrm{~min}$ (A), $21 \mathrm{~min}$ (B), $61 \mathrm{~min}$ (C) and 1 day (D) of reaction time in experiments performed from 10 to 80 ${ }^{\circ} \mathrm{C}$, showing the transformation of amorphous calcium magnesium carbonate (ACMC) into high $\mathrm{Mg}$-calcite $(\mathrm{HMC})$ at $\leq 60{ }^{\circ} \mathrm{C}$ and into $\mathrm{HMC}$ and hydromagnesite (HMG) at $80^{\circ} \mathrm{C}$ (see Table 1).

reaction time compared to higher temperature experiments (Fig. 4A-C, Table 2). Moreover, the obtained data from experiments performed at lower temperatures show a preferential release of $\mathrm{Mg}$ ions into the solution, resulting in ACMCs with slightly lower $\mathrm{Mg}$ contents (e.g. $46 \mathrm{~mol} \% \mathrm{Mg}$ in $\mathrm{T}_{-} 10^{\circ} \mathrm{C}$ ) compared to original composition of the synthetic ACMC material introduced in the reactors (48 $\mathrm{mol} \% \mathrm{Mg}$ ) (Fig. 4D).

After a short initial homogenization period between the ACMC material and the solution, the $\mathrm{pH}$ of the experimental solutions was adjusted to $7.58 \pm 0.04$ by automatic titration of $\mathrm{HCl}$ solution (Fig. S2†). The adjustment of the $\mathrm{pH}$ resulted in the further dissolution of ACMC, which causes an increase in alkalinity, $\mathrm{Ca}$ and $\mathrm{Mg}$ concentrations of the experimental solutions between 0.3 and $5 \mathrm{~min}$ (Fig. 4A-C). After about $5 \mathrm{~min}$, the $\mathrm{Ca}$ and alkalinity concentrations of the experimental solutions decrease (Fig. 4A and $\mathrm{C}$ ) due to the transformation of ACMC into crystalline $\mathrm{Ca}-\mathrm{Mg}$ carbonate phases (Fig. 2). With the exception of experiment $\mathrm{T}_{-} 80{ }^{\circ} \mathrm{C}$, the aqueous $\mathrm{Mg}$ concentrations of the solutions increase in the same time frame (Fig. 4B). The net release of $\mathrm{Mg}$ into the solution with an uptake of $\mathrm{Ca}$ into the solid during the ACMC transformation step results in HMCs with lower $\mathrm{Mg}$ contents compared to that of the initial ACMC precursor in experiments performed at $\leq 60{ }^{\circ} \mathrm{C}$ (Fig. 4D). In contrast, in experiment $\mathrm{T} \_80{ }^{\circ} \mathrm{C}$, the $\mathrm{Mg}$ content of the bulk solid increases slightly during the ACMC transformation step (Fig. 4D), due to the formation of $\mathrm{HMG}\left(\mathrm{Mg}_{5}\left(\mathrm{CO}_{3}\right)_{4}(\mathrm{OH})_{2} \cdot 4 \mathrm{H}_{2} \mathrm{O}\right)$ beside $\mathrm{HMC}$ and ARG (Table 1, Fig. S3 $\dagger$ ). Note that in experiment $\mathrm{T}_{-} 40{ }^{\circ} \mathrm{C}$, the $\mathrm{Mg}$ content of the bulk solid increased between 1 week and 2 months of reaction time, owing to the additional formation of HMG at this stage of the experiment (Fig. 4D).

At higher temperatures, the transformation of ACMC into HMC occurs faster as revealed by XRD and SEM observations (Fig. 2 and 3). This is further supported by the temporal evolution of $\mathrm{pH}$ and $\mathrm{HCl}$ solution addition derived from titration data (Fig. S2 $\dagger$ ). In experiments performed at $\leq 60{ }^{\circ} \mathrm{C}$, 

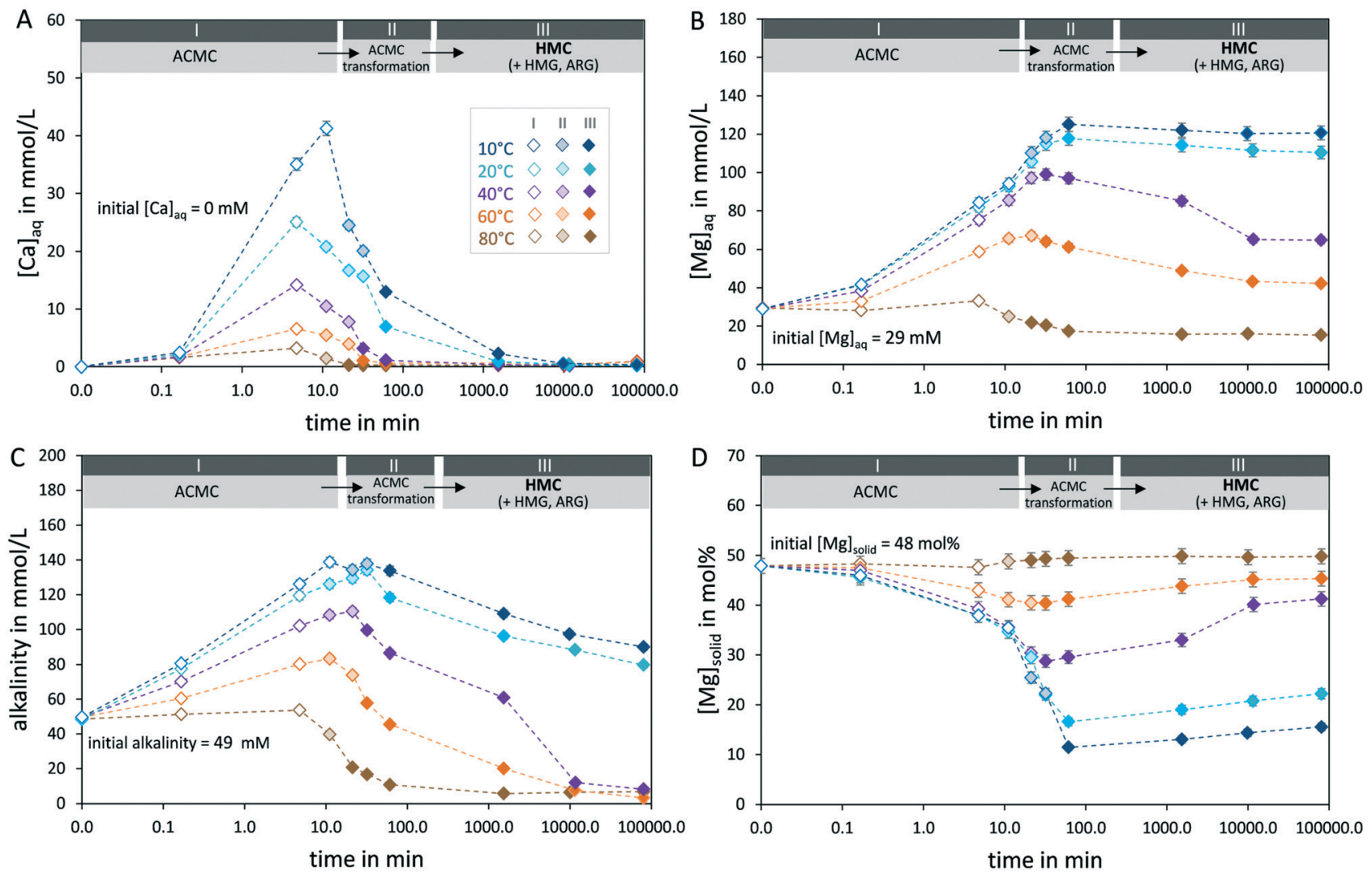

Fig. 4 Concentration of calcium (A), magnesium (B), alkalinity (C) of the solution and $\mathrm{Mg}$ content of the bulk solid (D) (see eqn 1) during amorphous calcium magnesium carbonate (ACMC) transformation into high $\mathrm{Mg}$-calcite (HMC) and in case partly into hydromagnesite (HMG) and aragonite (ARG) (see Table 1) at 10, 20, 40,60 and $80^{\circ} \mathrm{C}$. Stage I: ACMC is the sole solid phase (open diamonds); stage II: ACMC transforms to the crystalline phases (shaded diamonds); stage III: solid phase is crystalline (solid diamonds). Note that the $\mathrm{pH}$ of the solution was adjusted to $7.58 \pm$ 0.04 within $\leq 3$ min by computer-controlled titration of a $2 \mathrm{M} \mathrm{HCl}$ solution (Fig. S2†).

our data reveal that additional amounts of $\mathrm{HCl}$ solution were automatically added into the experimental solution to keep the $\mathrm{pH}$ constant at $7.58 \pm 0.04$ during the transformation of ACMC into HMC (Fig. S2A-D $\dagger$ ). The rise in $\mathrm{pH}$ and consequent titration of $\mathrm{HCl}$ may be explained by a fast dissolution of ACMC and slow precipitation of HMC during the ACMC transformation step. At higher temperatures, the $\mathrm{HCl}$ solution was added into the experimental solution in shorter periods of time (e.g. 17 min in $\mathrm{T}_{-} 60^{\circ} \mathrm{C}$ ) than at lower temperatures (e.g. $34 \mathrm{~min}$ in $\mathrm{T} \_20^{\circ} \mathrm{C}$ ), indicating that the transformation of ACMC into HMC occurs faster at elevated temperatures. Note that in experiment T_80 ${ }^{\circ} \mathrm{C}$, where ACMC transformed into HMC, HMG and ARG (Fig. 2E, Table 1), no additional $\mathrm{HCl}$ was added into the solution (Fig. S2E $\dagger$ ). In the latter case, the $\mathrm{pH}$ decreased slightly from 7.59 to 7.41 during the ACMC transformation step.

\section{Discussion}

\subsection{Effect of temperature on the Mg content of HMC formed via ACMC with near-dolomite stoichiometry}

Earlier studies showed a strong correlation between the physicochemical parameters of the initial solution used for
ACMC synthesis and the amount of $\mathrm{Mg}$ incorporated into ACMC and the final HMC. ${ }^{31,37,49,51}$ In this context, it has been suggested that tuning the amount of $\mathrm{Mg}$ in ACMC controls the amount of $\mathrm{Mg}$ incorporated into HMC. In contrast, the results of this study show that the $\mathrm{Mg}$ content of the HMC is by far not pre-determined by the $\mathrm{Mg}$ content of the initial ACMC ( $48 \mathrm{~mol} \% \mathrm{Mg}$ ) that was introduced into the solution (Fig. 5A). In experiments performed at temperatures $\leq 40{ }^{\circ} \mathrm{C}$, the $\mathrm{Mg}$ content of the final $\mathrm{HMC}$ is significantly lower (e.g. $18 \mathrm{~mol} \% \mathrm{Mg}$ in experiment $\mathrm{T} \_20^{\circ} \mathrm{C}$ ) than of the initial ACMC, whereas at higher temperatures $\left(\geq 60{ }^{\circ} \mathrm{C}\right.$ ), the final HMCs reach $\mathrm{Mg}$ contents comparable to those of VHMC (40 mol\%; Fig. 5A). These findings clearly document that the $\mathrm{Mg}$ content of the forming calcite is strongly regulated by the reaction temperature prevailing during ACMC transformation. It is generally acknowledged that the transformation mechanism of ACMC into (V)HMC involves (i) dissolution of ACMC and (ii) nucleation and crystal growth of (V)HMC. ${ }^{31,36,40,51}$ The relationship in Fig. 5A suggests that the $\mathrm{Mg}$ content of calcite forming at the ACMCsolution interface is significantly controlled by the temperature-dependent dehydration kinetic of aqueous $\mathrm{Mg}^{2+}$. The incorporation of $\mathrm{Mg}$ into anhydrous carbonates is generally postulated to be kinetically limited under low- 

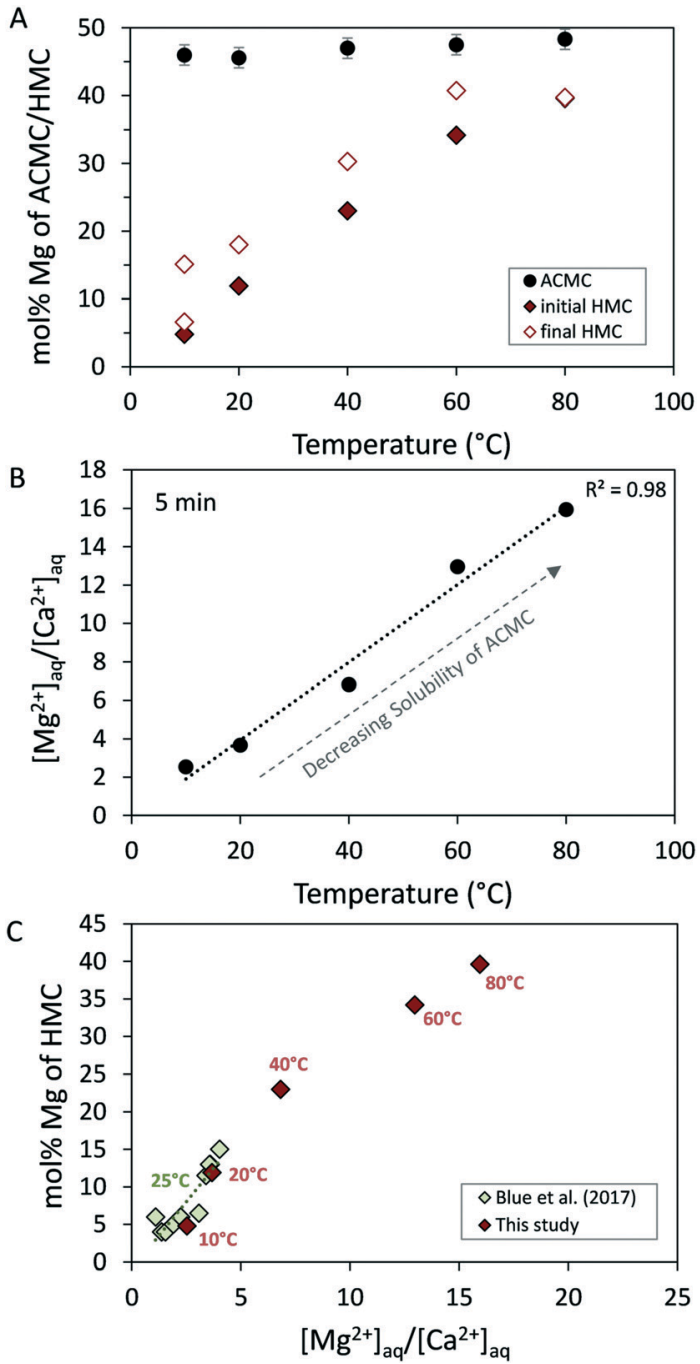

Fig. 5 (A) Temperature of the solution versus the $\mathrm{Mg}$ content of (i) ACMC obtained at $0.3 \mathrm{~min}$ of reaction time ([Mg] $]_{\text {solid }}$ values in Table 2), (ii) initial HMC obtained at $21 \mathrm{~min}$ in experiment T_10 ${ }^{\circ} \mathrm{C}$ and $11 \mathrm{~min}$ in experiments performed at $\geq 20^{\circ} \mathrm{C}$ and (iii) final $\mathrm{HMC}$ obtained at 1 day of reaction time. Note here that the $\mathrm{Mg}$ contents of HMCs were calculated from the $d_{104}$ values of calcite XRD peaks $\left([\mathrm{Mg}]_{\text {XRD }}\right.$ values in Table 1), whereas the Mg content of ACMC was calculated from solid digestion ([Mg $]_{\text {solid }}$ values in Table 2). (B) Temperature of the solution versus the $\mathrm{Mg}^{2+} / \mathrm{Ca}^{2+}$ ratio of the solution at $5 \mathrm{~min}$ of reaction time (Table $\mathrm{S} 2 \uparrow$ ). (C) $\mathrm{Mg}^{2+} / \mathrm{Ca}^{2+}$ ratio of the solution at $5 \mathrm{~min}$ versus the $\mathrm{Mg}$ content of (i) initial HMC from this study, of initial HMC from experiments conducted at stirred conditions reported by Blue et al. ${ }^{51}$

temperature conditions, due to the strong hydration of $\mathrm{Mg}^{2+}$ compared to $\mathrm{Ca}^{2+} \cdot{ }^{20,52}$ In contrast, higher temperatures reduce the $\mathrm{Mg}$-solvation energy barrier and favour anhydrous Ca-Mg-carbonate formation. ${ }^{53}$ Thus, the amount of $\mathrm{Mg}$ incorporated into calcite formed via ACMC is enhanced at higher reaction temperatures (Fig. 5A).

The obtained results further support previous observations $^{51}$ that the incorporation of $\mathrm{Mg}$ into calcite formed via ACMC is controlled by the $\mathrm{Mg}^{2+} / \mathrm{Ca}^{2+}$ ratio of the reactive solution at the time of transformation. Blue et al. ${ }^{51}$ synthesized ACMCs with different $\mathrm{Mg}$ contents under constant $\mathrm{pH}$ conditions ( $\mathrm{pH}$ 8.3-9.1) using a mixed flow reactor and investigated their crystallization pathway in aqueous solution under stirred and unstirred conditions. Their results document a positive correlation between the $\mathrm{Mg}$ content of calcite and the $\mathrm{Mg}^{2+} / \mathrm{Ca}^{2+}$ ratio of the solution from which the mineral formed. In the experimental setup used in the present study, $\mathrm{Mg}^{2+}$ and $\mathrm{CO}_{3}{ }^{2-}$ ions were present in the initial solution, whereas $\mathrm{Ca}^{2+}$ ions exclusively originated from the dissolution of the ACMC. At higher temperatures, lower amounts of ACMC dissolved in the $\mathrm{NaHCO}_{3}-\mathrm{MgCl}_{2}$ solution as indicated by less $\mathrm{Ca}^{2+}$ ions released into the reactive solution (Fig. 4A). This can be explained by the anticorrelation between amorphous carbonate mineral solubility and temperature (for ACC: Brečević \& Nielsen ${ }^{28}$ ). Thus, at $5 \mathrm{~min}$ of reaction time, the reactive solutions exhibit higher aqueous $\mathrm{Mg}^{2+} / \mathrm{Ca}^{2+}$ ratios as a function of increasing temperature (Fig. 5B; Table S2 $\dagger$ ). Indeed, by comparing the $\mathrm{Mg}$ content of the initial HMC with the $\mathrm{Mg}^{2+} / \mathrm{Ca}^{2+}$ ratio of the solution after its reaction with the ACMC, we find a good agreement of the results obtained at $25^{\circ} \mathrm{C}$ and those reported by Blue et al. ${ }^{51}$ (Fig. 5C).

During the ongoing transformation of ACMC into HMC, the $\mathrm{Mg}^{2+} / \mathrm{Ca}^{2+}$ ratio of the solution increases (Table $\mathrm{S} 2 \dagger$ ) due to stronger uptake of $\mathrm{Ca}^{2+}$ compared to $\mathrm{Mg}^{2+}$ from the solution into the solid. This increasing $\mathrm{Mg}^{2+} / \mathrm{Ca}^{2+}$ ratio likely results in the formation of HMC with higher $\mathrm{Mg}$ contents as a function of reaction time $\left([\mathrm{Mg}]_{\mathrm{XRD}}\right.$ values in Table 1$)$. Hence, the final HMCs exhibit higher $\mathrm{Mg}$ contents compared to the initial HMCs (Fig. 5A). This effect is temporally better resolved at low temperatures, due to slower transformation kinetics of ACMC into HMC (Table 1). For example, at $20^{\circ} \mathrm{C}$ the $\mathrm{Mg}$ content of HMC increases slowly from 12 to $17 \mathrm{~mol} \%$ between 11 and $61 \mathrm{~min}$ of reaction time (Table 1). In contrast, at higher temperatures, the transformation of ACMC into HMC occurs faster and the transition from lower to higher $\mathrm{Mg}$ contents for HMCs occurs in shorter time intervals (Table 1).

The positive relationship between aqueous $\mathrm{Mg}^{2+} / \mathrm{Ca}^{2+}$ ratios and $\mathrm{Mg}$ content of the forming HMC from ACMC transformation (Fig. 5C) indicates that the $\mathrm{Mg}$ content into calcite might be enhanced to higher levels by increasing the $\mathrm{Mg}^{2+} / \mathrm{Ca}^{2+}$ ratio of the reactive transformation solution. However, experimental studies at $25{ }^{\circ} \mathrm{C}$ and moderate $\mathrm{pH}$ conditions (8.3-9.1) documented that at higher prevailing $\mathrm{Mg}^{2+} / \mathrm{Ca}^{2+}$ ratios (>4: Blue et al. $;^{51} \geq 8$ : Purgstaller et al. ${ }^{42}$ ), ACMC transforms into hydrous $\mathrm{Ca}$ - or $\mathrm{Mg}$-carbonate phases, i.e. monohydrocalcite and nesquehonite, rather than into calcite, due to the inhibition of the latter. ${ }^{50,51}$ These observations suggest a maximum limit of about $20 \mathrm{~mol} \% \mathrm{Mg}$ in calcite formed via the amorphous pathway. ${ }^{49-51}$ It should be emphasized that when ACMC transforms under unstirred conditions, $\mathrm{Mg}$ contents of up to $30 \mathrm{~mol} \% \mathrm{Mg}$ for HMC were reported in experimental studies conducted at moderate $\mathrm{pH}$ conditions and ambient temperatures. ${ }^{51,54}$ However the process by which physical mixing influences the formation of distinct crystalline $\mathrm{Ca}-\mathrm{Mg}$-carbonates and the $\mathrm{Mg}$ content of calcite is still poorly understood and needs further investigations. 

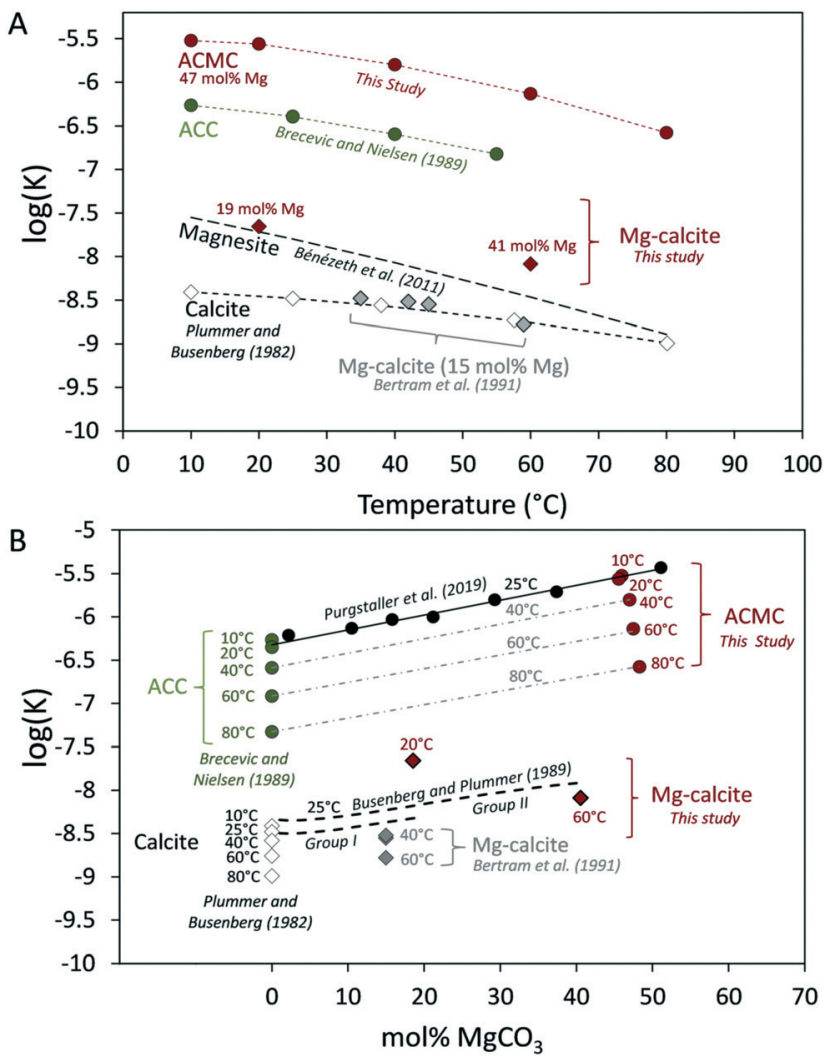

Fig. 6 Solublity product ( $K$ ) of ACC (Brecevic and Nielsen ${ }^{28}$ ), ACMC (present study and Purgstaller et al. ${ }^{33}$ ), calcite (Plummer and Busenberg ${ }^{55}$ ), Mg-calcite (present study, Busenberg and Plummer ${ }^{19}$ and Bertram et $a{ }^{57}$ ) and magnesite (Bénézeth et al. ${ }^{56}$ ) as a function of (A) temperature and (B) $\mathrm{Mg}$ mole fraction. The $K$ of ACMC and $\mathrm{Mg}$ calcite was calculated according to eqn 2 .

\subsection{Solubility considerations of ACMC and HMC}

At higher reaction temperatures, less ACMC dissolved in the $\mathrm{NaHCO}_{3}-\mathrm{MgCl}_{2}$ solutions as it is indicated by the lower concentrations of $\mathrm{Ca}, \mathrm{Mg}$ and $\mathrm{CO}_{3}$ ions in the reactive solutions at $0.3 \mathrm{~min}$ of reaction time (Fig. $4 \mathrm{~A}$ ). In order to assess the effect of temperature on the solubility $(K)$ of ACMC, the activities of $\mathrm{Ca}^{2+}, \mathrm{Mg}^{2+}$ and $\mathrm{CO}_{3}{ }^{2-}$ ions in the reactive solution (Table S3†) and the ACMC stoichiometry (at $0.3 \mathrm{~min}$ ) were used to calculate $K_{\mathrm{ACMC}}$ values according to eqn 2 (see also Purgstaller et $a l^{33}{ }^{33}$ ). The obtained $K_{\mathrm{ACMC}}$ values for ACMC with $47.0 \pm 1.5 \mathrm{~mol} \% \mathrm{Mg}$ $(t=0.3 \mathrm{~min})$ indicate that the solubility of ACMC is lower at higher temperature (Fig. 6A), analogous to the temperaturedependent solubility of ACC determined by Brečević and Nielsen. ${ }^{28}$ A similar behaviour is also well known for anhydrous carbonate minerals such as calcite ${ }^{55}$ and magnesite ${ }^{56}$ which exhibit lower $K$ values at higher temperatures (Fig. 6A). The relationship between the solubility of ACMC (with 47.0 \pm 1.5 $\mathrm{mol} \% \mathrm{Mg}$ ) and temperature ( $\mathrm{T}$ in Kelvin) can be described by the polynomial function:

$$
\begin{aligned}
\log \left(K_{\mathrm{ACMC}}\right)= & -0.0001434 \pm 0.0000137 \mathrm{~T}^{2}+0.0760 \pm 0.0087 \mathrm{~T} \\
& -15.537 \pm 1.375 \quad\left(R^{2}=0.99\right)
\end{aligned}
$$

It is strongly emphasized that in the present study the experimental data for calculating $K_{\mathrm{ACMC}}$ values are limited (Table S $3 \uparrow$ ) and further experimental work is needed to verify the obtained relationship between $K_{\mathrm{ACMC}}$ and temperature (Fig. 6A).

As it can be seen in Fig. 6A the solubility products of ACMC are higher compared to Mg-free ACC at any temperature suggesting that ACMC is more soluble than ACC. This feature can be attributed to the increasing water content and changes in short-range order, as $\mathrm{Ca}$ is substituted by $\mathrm{Mg}$ in the amorphous structure. ${ }^{33}$ The relationship between the solubility of ACMC and its $\mathrm{Mg}$ content is displayed in Fig. 6B. Note that the slopes of the regression lines between the $K_{\mathrm{ACC}}$ value of Brečević and Nielsen ${ }^{28}$ and the $K_{\mathrm{ACMC}}$ value of this study are similar at 10 , 20, 40, 60 and $80{ }^{\circ} \mathrm{C}$ (slope $=0.01634 \pm 0.00066$; Fig. $6 \mathrm{~B}$ and Table $\mathrm{S} 4 \dagger$ ) and are in good agreement with the slope value of the linear relationship between $\mathrm{K}_{\mathrm{ACMC}}$ and the $\mathrm{Mg}$ content of ACMC at $25{ }^{\circ} \mathrm{C}$ (slope $=0.01602 ; \mathrm{Mg}$ content of $\mathrm{ACMC}=2$ to $51 \mathrm{~mol} \%$, Table $\mathrm{S} 4 \dagger$ ) presented by Purgstaller et al. ${ }^{33}$ Considering the close agreement between $K$ values obtained in this study and those of Brečević and Nielsen ${ }^{28}$ and Purgstaller et al. $^{33}$ a quantitative description of the variations of $K_{\mathrm{ACMC}}$ with temperature and $\mathrm{Mg}$ content of ACMC can be obtained starting from the relationship between ACC solubility $\left(K_{\mathrm{ACC}}\right)$ and temperature ( $\mathrm{T}$ in Kelvin) determined by Brečević and Nielsen: ${ }^{28}$

$$
\log \left(K_{\mathrm{ACC}}\right)=-0.0001096 \mathrm{~T}^{2}+0.0545 \mathrm{~T}-12.919
$$

Based on the assumption that the relative increase of $K_{\mathrm{ACMC}}$ values as a function of the $\mathrm{Mg}$ content is independent of temperature and can be described by the same linear function with an average slope of $0.01629 \pm 0.00060$ (see Table S4 $\dagger$ ), the variation of the solubility of ACMC with temperature and $\mathrm{Mg}$ content can be obtained from the equation:

$$
\begin{aligned}
\log \left(K_{\mathrm{ACMC}}\right)= & 0.01629 \times[\mathrm{Mg}]_{\mathrm{ACMC}}-0.0001096 \mathrm{~T}^{2}+0.0545 \mathrm{~T} \\
& -12.919
\end{aligned}
$$

where $[\mathrm{Mg}]_{\mathrm{ACMC}}$ refers to the $\mathrm{Mg}$ content of ACMC in mol\% (eqn 1) and $\mathrm{T}$ is the temperature reported in Kelvin. Note that the obtained relationship between $K_{\mathrm{ACMC}},[\mathrm{Mg}]_{\mathrm{ACMC}}$ and temperature is only valid for the studied ranges of $[\mathrm{Mg}]_{\mathrm{ACMC}}$ $=0-51 \mathrm{~mol} \%$ and $\mathrm{T}=10-80{ }^{\circ} \mathrm{C}$ of the present study, Brečević and Nielsen ${ }^{28}$ and Purgstaller et al. ${ }^{33}$

The dependence of ACMC solubility on the $\mathrm{Mg}$ content is similar to that of $\mathrm{Mg}$-calcite (above $4 \mathrm{~mol} \% \mathrm{Mg}$ ), where high $\mathrm{Mg}$ contents in calcite result in higher solubilities (for $25^{\circ} \mathrm{C}$ : Busenberg and Plummer; ${ }^{19}$ Fig. 6B). However, the impact of temperature on the solubility of HMC is not fully elucidated and to our knowledge only Bertram et al. (1991) ${ }^{57}$ studied the solubility of synthetic Mg-calcites with 1.9 to $15 \mathrm{~mol} \% \mathrm{Mg}$ between 25 to $64{ }^{\circ} \mathrm{C}$ and showed that the decrease in solubility of $\mathrm{Mg}$-calcite with increasing temperature parallels 
that of calcite (see $K$ data of $\mathrm{Mg}$-calcite with $15 \mathrm{~mol} \% \mathrm{Mg}$ in Fig. 6A). No experimental data, however, exist for the solubility dependence of HMC with $>15 \mathrm{~mol} \% \mathrm{Mg}$ at elevated temperatures. Fig. 6A and B shows the calculated $K$ values of the final HMC $\left(K_{\mathrm{HMC}}\right)$ from experiment $\mathrm{T} \_20^{\circ} \mathrm{C}$ and $\mathrm{T} \_60^{\circ} \mathrm{C}$. The $K$-values were calculated using the chemical data and the HMC stoichiometry (based on $[\mathrm{Mg}]_{\mathrm{XRD}}$, Table 1) at 1 week and 2 months of reaction time (Table S3†). At this time the system achieved near-equilibrium conditions (Table 2). Note that $K_{\mathrm{HMC}}$ values were not calculated in experiments $\mathrm{T}_{-} 10^{\circ} \mathrm{C}$, $\mathrm{T} \_40{ }^{\circ} \mathrm{C}$ and $\mathrm{T} \_80{ }^{\circ} \mathrm{C}$ because the final solids of $\mathrm{T} \_10{ }^{\circ} \mathrm{C}$ consist of two $\mathrm{Mg}$-calcites with different $\mathrm{Mg}$ contents (Fig. 2A) and those of $\mathrm{T}_{-} 40^{\circ} \mathrm{C}$ and $\mathrm{T} \_80^{\circ} \mathrm{C}$ include HMG (6$15 \mathrm{wt} \%$, Table 1). As it can be seen in Fig. 6B, the HMC formed via ACMC at $20{ }^{\circ} \mathrm{C}$ (with $18 \mathrm{~mol} \% \mathrm{Mg}$ ) is significantly more soluble $\left(\log \left(K_{\mathrm{HMC}}\right)=-7.83\right)$ than the biogenic and synthetic Mg-calcites of group II reported by Busenberg and Plummer, ${ }^{19}$ which exhibit similar $\mathrm{Mg}$ contents $\left(\right.$ e.g. $\log \left(K_{\mathrm{HMC}}\right)$ $=-8.16$ for biogenic $\mathrm{Mg}$-calcite with $19 \mathrm{~mol} \% \mathrm{Mg}$ at $25^{\circ} \mathrm{C}$ ). Note that Busenberg and Plummer ${ }^{19}$ distinguished two groups of $\mathrm{Mg}$-calcites with distinct solubilities, reflecting crystal structure defects (Fig. 6B). Group I consists of metamorphic and hydrothermal Mg-calcites and synthetic Mg-calcites prepared at high temperatures and pressures or low temperatures and low supersaturations (saturation index $\leq 0.2$ ). Group II Mg-calcites are of either biogenic origin or synthetic Mg-calcites prepared at high supersaturations (saturation index $\geq 0.5$ ). The $\mathrm{Mg}$-calcites of group I are thought to be relatively free of structural defects, whereas group II $\mathrm{Mg}$-calcites were described as more defective $\mathrm{Mg}$ calcites which exhibit higher solubilities. The discrepancy between the reported solubility value of Busenberg and Plummer $^{19}$ and of the present study might be explained by different physical defects originating from rapid crystal growth during HMC formation. Considering an ACMC transformation step, the solution in equilibrium with ACMC is highly supersaturated with respect to calcite (saturation index $>2$ (ref. 31) and 49)). Such high calcite supersaturation degrees probably promote rapid precipitation of HMC at the ACMC-solution interface. Indeed, in the present study, ACMC transformed into nanocrystalline $\mathrm{HMC}$ at relatively short time intervals ( $<60 \mathrm{~min}$, Fig. 2 and 3 ). These solids are likely more defective and thus exhibit higher solubilities compared to well-crystallized HMC (Fig. 6B). The elevated solubilities of nanocrystalline HMC appears to be consist with recent results of Davis et al. ${ }^{58}$ who demonstrated, based on microscopic observations, enhanced solubilities of $\mathrm{Mg}$ calcites at the nanometric scale.

\section{Conclusions}

In the present study, the transformation of ACMC with neardolomite stoichiometry $(47.9 \pm 1.5 \mathrm{~mol} \% \mathrm{Mg})$ into HMC was investigated in a $\mathrm{MgCl}_{2}-\mathrm{NaHCO}_{3}$ buffered solution at $\mathrm{pH} 7.6$ and in the temperature range from 10 to $80 \pm 1^{\circ} \mathrm{C}$. The results provide an advanced understanding of the complex interplay between the chemical composition of ACMC, the corresponding solution and the finally formed $\mathrm{Mg}$-calcite. At first, the experimental data indicate that the apparent solubility of ACMC is lower at higher temperature and the relative increase of solubility as a function of the $\mathrm{Mg}$ content of ACMC is similar from 10 to $80{ }^{\circ} \mathrm{C}$ which can be assessed by eqn 5 . At ambient temperatures, the $\mathrm{Mg}$ content of $\mathrm{HMC}$ formed via the transformation of ACMC is as low as 18 mol\%, whereas at 60 and $80{ }^{\circ} \mathrm{C}$, the final HMCs reach $\mathrm{Mg}$ levels comparable with those of VHMC (40 mol\%). Hence, the $\mathrm{Mg}$ content of the $\mathrm{HMC}$ is not pre-determined by the $\mathrm{Mg}$ content of the amorphous precursor, but strongly influenced by the reaction temperature during ACMC transformation. The transformation of ACMC to HMC proceeds via a dissolution and re-precipitation mechanism where at higher temperatures the amount of $\mathrm{Mg}$ incorporated into calcite is enhanced due to (i) the reduced solvation energy barrier of aqueous $\mathrm{Mg}^{2+}$ and (ii) the high $\mathrm{Mg}^{2+} / \mathrm{Ca}^{2+}$ ratio of the reactive solution after its reaction with the ACMC. The high $\mathrm{Mg}^{2+}$ / $\mathrm{Ca}^{2+}$ ratio of the latter solution can be explained by low solubility of ACMC at elevated temperatures. The obtained solubilities of the final HMC are higher compared to those of well-crystalline Mg-bearing calcites, which is most likely caused by nanometric-sized HMC crystals with structural defects originated from fast crystal growth.

\section{Abbreviations}

ACC Amorphous calcium carbonate

ACMC Amorphous calcium magnesium carbonate

ARG Aragonite

FWHM Full-width at half-maximum

ICP-OES Inductively coupled plasma optical emission spectrometry

LMC Low Mg-calcite

HMC High Mg-calcite

HMG Hydromagnesite

SEM Scanning electron microscope

TGA Thermogravimetric analyses

XRD X-ray diffraction

\section{Conflicts of interest}

There are no conflicts to declare.

\section{Acknowledgements}

The authors are thankful to Stefanie Eichinger for her support with the analytical work and to Isaac Kell-Duivestein for providing the Coorong dolomite sample. Chemical analyses were conducted at NAWI Graz Central Lab for Water, Minerals and Rocks. This work has been financially supported by Austrian Science Fund (FWF) project number T920-N29, and in part by DFG-FWF collaborative research initiative CHARON II (DFG Forschergruppe 1644; FWF I3028-N29) and by NAWI Graz. 


\section{References}

1 J. W. Morse and F. T. Mackenzie, in Developments in Sedimentology 48, Elsevier, 1990, p. 725.

2 R. J. Reeder, in Reviews in Mineralogy, Mineralogical Society of America, 11th edn, 1990, p. 399.

3 F. T. Mackenzie, W. D. Bischoff, F. C. Bishop, M. Loijens, J. Schoonmaker and R. Wollast, Carbonates Mineral. Chem., 1983, pp. 97-144.

4 W. D. Bischoff, S. K. Sharma and F. T. MacKenzie, Am. Mineral., 1985, 70, 581-589.

5 J. M. Gregg, D. L. Bish, S. E. Kaczmarek and H. G. Machel, Sedimentology, 2015, 1749-1769.

6 M. E. Tucker and V. P. Wright, Carbonate Sedimentology, Blackwell Scientific Publications, Boston, 1990.

7 V. Mavromatis, R. Botz, M. Schmidt, V. Liebetrau and C. Hensen, Int. J. Earth Sci., 2014, 103, 1831-1844.

8 A. Paul and S. W. Lokier, Sediment. Geol., 2017, 352, 1-13.

9 S. Bentov and J. Erez, Geochem., Geophys., Geosyst., 2006, 7, Q01P08.

10 S. Raz, S. Weiner and L. Addadi, Adv. Mater., 2000, 12, 38-42.

11 M. C. Nash, U. Troitzsch, B. N. Opdyke, J. M. Trafford, B. D. Russell and D. I. Kline, Biogeosciences, 2011, 8, 3331-3340.

12 S. Gayathri, R. Lakshminarayanan, J. C. Weaver, D. E. Morse, R. Manjunatha Kini and S. Valiyaveettil, Chem. - Eur. J., 2007, 13, 3262-3268.

13 J. H. Schroeder, E. J. Dwornik and J. J. Papike, Geol. Soc. Am. Bull., 1969, 80, 1613-1616.

14 Y. Ma, B. Aichmayer, O. Paris, P. Fratzl, A. Meibom, R. A. Metzler, Y. Politi, L. Addadi, P. U. P. A. Gilbert and S. Weiner, Proc. Natl. Acad. Sci. U. S. A., 2009, 106, 6048-6053.

15 F. C. Furman, R. E. Woody, M. A. Rasberry, D. J. Keller and J. M. Gregg, Proc. Sixth Symp. Geol. Bahamas, 1993, 47-54.

16 C. Vasconcelos and J. A. McKenzie, J. Sediment. Res., 1997, 67, 378-390.

17 J. B. Sumrall, E. B. Larson and J. E. Mylroie, Carbonates Evaporites, 2017, 32, 123-133.

18 D. Fussmann, A. J. E. Von Hoyningen-Huene, A. Reimer, D. Schneider, H. Babková, R. Peticzka, A. Maier, G. Arp, R. Daniel and P. Meister, Biogeosciences, 2020, 17, 2085-2106.

19 E. Busenberg and L. Niel Plummer, Geochim. Cosmochim. Acta, 1989, 53, 1189-1208.

20 F. Lippmann, Sedimentary carbonate minerals, SpringerVerlag Berlin, 1973, vol. 12.

21 R. A. Berner, Geochim. Cosmochim. Acta, 1975, 39, 489-504.

22 L. Fernandez-Diaz, A. Putnis, M. Prieto and C. V. Putnis, J. Sediment. Res., 1996, 66, 482-491.

23 K. E. Goetschl, B. Purgstaller, M. Dietzel and V. Mavromatis, Geochim. Cosmochim. Acta, 2019, 265, 505-519.

24 G. D. Markham, J. P. Glusker, C. L. Bock, M. Trachtman and C. W. Bock, J. Phys. Chem., 1996, 100, 3488-3497.

25 A. Bleuzen, P. A. Pittet, L. Helm and A. E. Merbach, Magn. Reson. Chem., 1997, 35, 765-773.

26 J. Schott, O. Pokrovsky and E. Oelkers, Rev. Mineral. Geochem., 2009, 70, 207-258.
27 T. Ogino, T. Suzuki and K. Sawada, J. Cryst. Growth, 1990, 100, 159-167.

28 L. Brečević and A. E. Nielsen, J. Cryst. Growth, 1989, 98, 504-510.

29 L. Addadi, S. Raz and S. Weiner, Adv. Mater., 2003, 15, 959-970.

30 Y. Politi, D. R. Batchelor, P. Zaslansky, B. F. Chmelka, J. C. Weaver, I. Sagi, S. Weiner and L. Addadi, Chem. Mater., 2010, 22, 161-166.

31 J. D. Rodriguez-Blanco, S. Shaw and L. G. Benning, Am. Mineral., 2015, 100, 1172-1181.

32 A. V. Radha, A. Fernandez-Martinez, Y. Hu, Y. S. Jun, G. A. Waychunas and A. Navrotsky, Geochim. Cosmochim. Acta, 2012, 90, 83-95.

33 B. Purgstaller, K. E. Goetschl, V. Mavromatis and M. Dietzel, CrystEngComm, 2019, 21, 155-164.

34 J. D. Rodriguez-Blanco, S. Shaw, P. Bots, T. Roncal-Herrero and L. G. Benning, J. Alloys Compd., 2012, 536, S477-S479.

35 C. J. Lin, S. Y. Yang, S. J. Huang and J. C. C. Chan, J. Phys. Chem. C, 2015, 119, 7225-7233.

36 J. M. Xto, H. Du, C. N. Borca, E. Amstad, J. A. Van Bokhoven and T. Huthwelker, Cryst. Growth Des., 2019, 19, 4385-4394.

37 X. Long, Y. Ma and L. Qi, Cryst. Growth Des., 2011, 11, 2866-2873.

38 H. Yang, S. Chai, Y. Zhang and Y. Ma, CrystEngComm, 2015, 18, 157-163.

39 M. Schmidt, S. Xeflide, R. Botz and S. Mann, Geochim. Cosmochim. Acta, 2005, 69, 4665-4674.

40 I. J. Kelleher and S. A. T. Redfern, Mol. Simul., 2002, 28, 557-572.

41 F. Konrad, F. Gallien, D. E. Gerard and M. Dietzel, Cryst. Growth Des., 2016, 16, 6310-6317.

42 B. Purgstaller, M. Dietzel, A. Baldermann and V. Mavromatis, Geochim. Cosmochim. Acta, 2017, 217, 128-143.

43 F. Konrad, B. Purgstaller, F. Gallien, V. Mavromatis, P. Gane and M. Dietzel, J. Cryst. Growth, 2018, 498, 381-390.

44 J. R. Goldsmith, D. L. Graf and H. C. Heard, Am. Mineral., 1961, 46, 453-459.

45 C. R. Blue and P. M. Dove, Geochim. Cosmochim. Acta, 2015, 148, 23-33.

46 G. Montes-Hernandez, F. Renard, R. Chiriac, N. Findling and F. Toche, Cryst. Growth Des., 2012, 12, 5233-5240.

47 W. Bischoff, F. Bishop and F. Mackenzie, Am. Mineral., 1983, 68, 1183-1188.

48 F. Zhang, H. Xu, H. Konishi and E. E. Roden, Am. Mineral., 2010, 95, 1650-1656.

49 B. Purgstaller, V. Mavromatis, A. Immenhauser and $\mathrm{M}$. Dietzel, Geochim. Cosmochim. Acta, 2016, 174, 180-195.

50 B. Purgstaller, F. Konrad, M. Dietzel, A. Immenhauser and V. Mavromatis, Cryst. Growth Des., 2017, 17, 1069-1078.

51 C. R. Blue, A. Giuffre, S. Mergelsberg, N. Han, J. J. De Yoreo and P. M. Dove, Geochim. Cosmochim. Acta, 2017, 196, 179-196.

52 V. Mavromatis, Q. Gautier, O. Bosc and J. Schott, Geochim. Cosmochim. Acta, 2013, 114, 188-203. 
53 F. Di Lorenzo, R. M. Rodríguez-Galán and M. Prieto, Mineral. Mag., 2014, 78, 1363-1372.

54 N. Han, C. R. Blue, J. J. De Yoreo and P. M. Dove, Procedia Earth Planet. Sci., 2013, 7, 223-227.

55 N. Plummer and E. Busenberg, Geochim. Cosmochim. Acta, 1982, 46, 1011-1040.
56 P. Bénézeth, G. D. Saldi, J. L. Dandurand and J. Schott, Chem. Geol., 2011, 286, 21-31.

57 M. A. Bertram, F. T. Mackenzie, F. C. Bishop and W. D. Bischoff, Am. Mineral., 1991, 76, 1889-1896.

58 K. J. Davis, P. M. Dove and J. J. De Yoreo, Science, 2000, 290, 1134-1137. 